\title{
Arithmetic and algebra word problems: Preservice teachers' content knowledge, attitudes, and appreciation of students' strategies
}

Marc D. Michael

West Virginia University

Follow this and additional works at: https://researchrepository.wvu.edu/etd

\section{Recommended Citation}

Michael, Marc D., "Arithmetic and algebra word problems: Preservice teachers' content knowledge, attitudes, and appreciation of students' strategies" (2005). Graduate Theses, Dissertations, and Problem Reports. 4175.

https://researchrepository.wvu.edu/etd/4175

This Dissertation is protected by copyright and/or related rights. It has been brought to you by the The Research Repository @ WVU with permission from the rights-holder(s). You are free to use this Dissertation in any way that is permitted by the copyright and related rights legislation that applies to your use. For other uses you must obtain permission from the rights-holder(s) directly, unless additional rights are indicated by a Creative Commons license in the record and/ or on the work itself. This Dissertation has been accepted for inclusion in WVU Graduate Theses, Dissertations, and Problem Reports collection by an authorized administrator of The Research Repository @ WVU.

For more information, please contact researchrepository@mail.wvu.edu. 


\title{
ARITHMETIC AND ALGEBRA WORD PROBLEMS: PRESERVICE TEACHERS' CONTENT KNOWLEDGE, ATTITUDES, AND APPRECIATION OF STUDENTS' STRATEGIES
}

\author{
Marc D. Michael \\ Dissertation submitted to the \\ College of Human Resources and Education \\ at West Virginia University \\ in partial fulfillment of the requirements \\ for the degree of \\ Doctor of Education \\ in \\ Curriculum and Instruction \\ Patricia Obenauf, Ph.D., Chair \\ Ronald Iannone, Ph.D. \\ Michael Mays, Ph.D. \\ Richard Walls, Ph.D. \\ Jaci Webb-Dempsey, Ph.D.
}

Department of Educational Theory and Practice

Morgantown, West Virginia

2005

Keywords: Algebraic reasoning, problem-solving, teacher education

Copyright 2005, Marc David Michael 


\title{
ABSTRACT \\ ARITHMETIC AND ALGEBRA WORD PROBLEMS: PRESERVICE TEACHERS' CONTENT KNOWLEDGE, ATTITUDES, AND APPRECIATION OF STUDENTS' STRATEGIES
}

\author{
Marc D. Michael
}

The arithmetic and algebraic word problem-solving skills, strategy preferences, and attitudes of preservice elementary and secondary teachers were investigated using a mixed methodology. Teachers' appreciations of student solutions were also examined. Prospective elementary teachers demonstrated flexible problem-solving behaviors while their secondary counterparts tended to prefer algebraic strategies exclusively. In general, the prospective teachers did not demonstrate a greater appreciation for those types of strategies that were typical to their level of training. When communicating the characteristics of an effective strategy, preservice teachers were concerned with organization and clarity rather than the mathematical relevance or appropriateness of the strategy itself. The findings indicate the need for an integrated approach to problem-solving instruction in teacher education programs and more attention to the critical issues surrounding students' transition from arithmetic to algebra. 
Table of Contents

\section{Chapter 1}

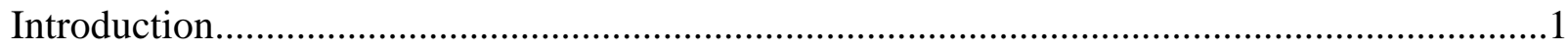

Problem Statement and Guiding Questions ...............................................................4

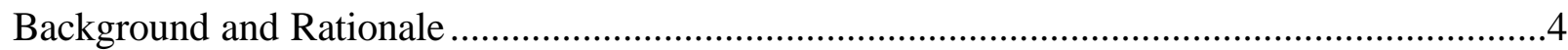

Chapter 2

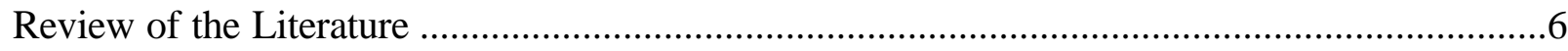

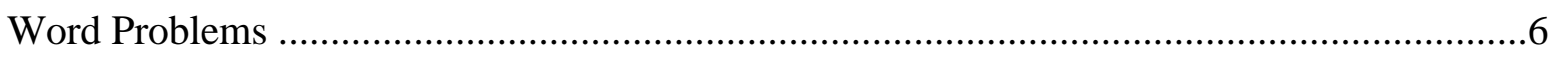

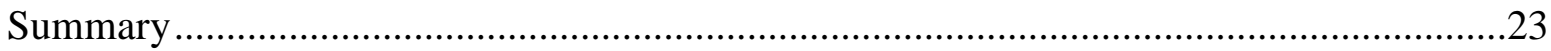

Preservice Teachers' Content Knowledge ..............................................................25

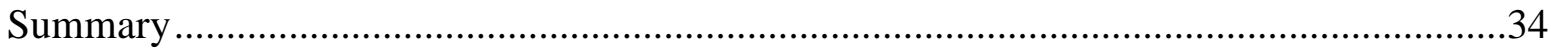

\section{Chapter 3}

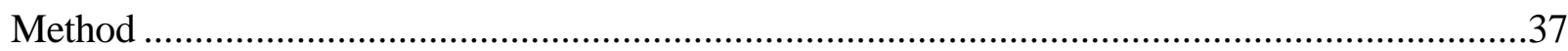

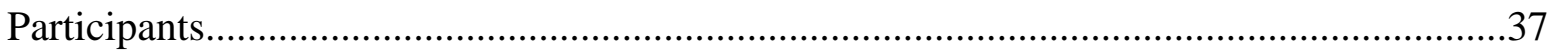

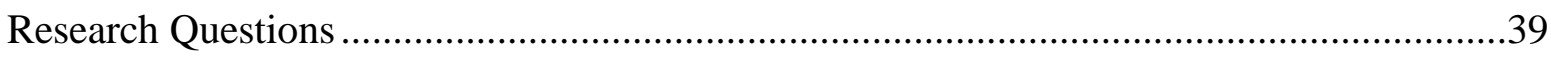

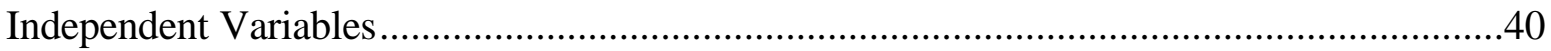

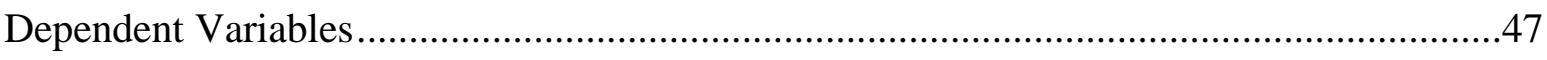

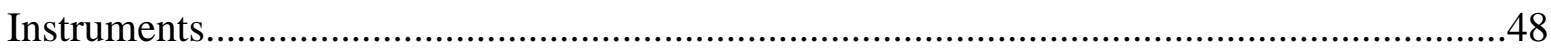

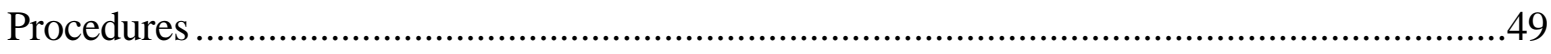

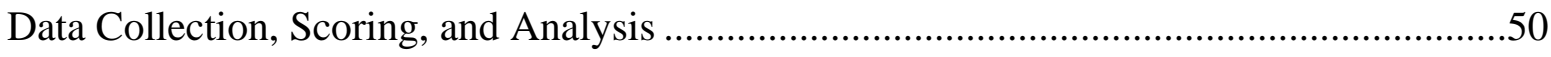


Chapter 4

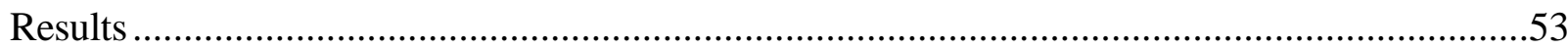

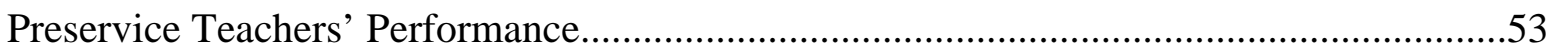

Preservice Teachers' Preferred Strategies ................................................................54

Preservice Teachers' Evaluations of Students' Solutions ...............................................58

Relation Between Problem Solving Behavior and Didactic Behavior .............................62

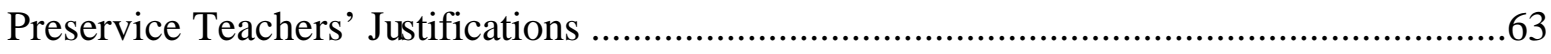

Interviews: A Closer Look at Preservice Teachers' Attitudes ........................................68

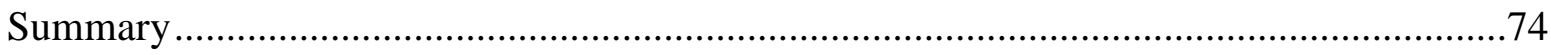

Chapter 5

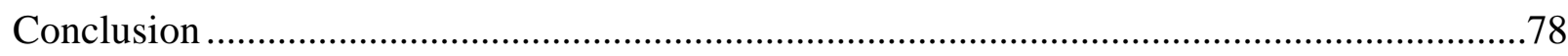

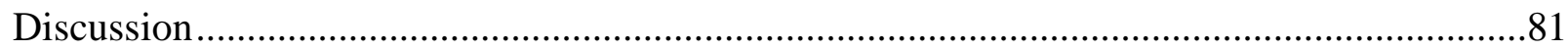

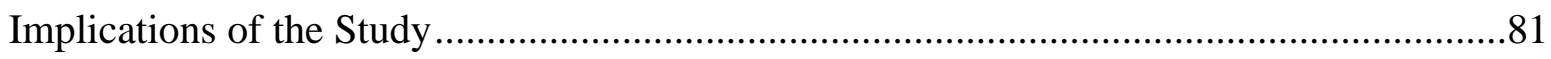

Recommendations for Teacher Education .......................................................... 83

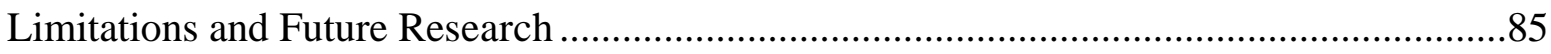

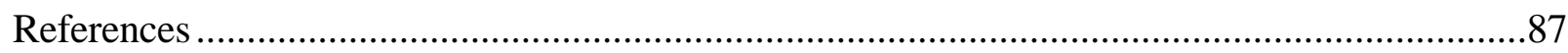

Appendix A: Word Problem Test Items ........................................................................ 97

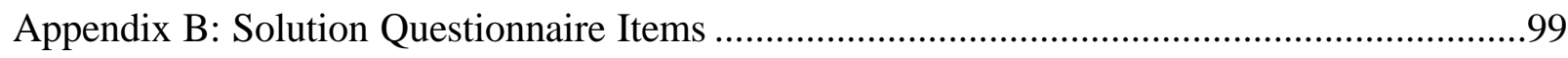

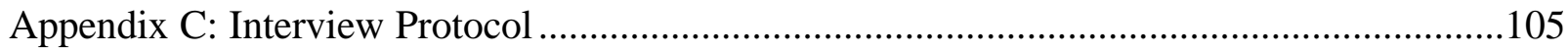




\section{Chapter 1}

\section{Introduction}

For most American students the formal learning of algebra, usually encountered in grade 8 or 9 , marks a transition from arithmetic to algebraic reasoning. According to Sutherland (in press) algebraic reasoning focuses on general mathematical objects, relationships and methods. In elementary school, teachers should provide students with an understanding of several basic mathematical concepts such as commutativity and associativity of operations, and the symmetric and transitive properties of the equality relation (Van Dooren, Verschaffel, \& Onghena, 2002). And they should develop various skills including representing word problems by equations, simplifying and comparing arithmetic equations, and solving open number sentences (Kieran, 1989). Much of what is learned in elementary mathematics is later generalized and formalized to build a foundation for algebraic reasoning and algebraic problem solving (Carpetnet \& Levi, 2000; Nathan \& Koedinger, 2000; Slavit, 1999).

Students' proper development of an algebraic method for solving problems is a complicated process and an important instructional task for teachers (Discussion document for the twelfth ICMI study, 2000; Filloy \& Sutherland, 1996). However, the introduction of algebraic reasoning tasks creates many difficulties for students, and is evinced by the efforts researchers have made to identify and minimize these difficulties (e.g., Brenner et al., 1997; Davis, 1989; Filloy \& Sutherland, 1996; Herscovics \& Linchevski, 1994; Kaput, 1989; Kieran, 1989; 1992; Reed, 1999; Stienberg, Sleeman \& Ktorza, 1990). In particular, Kieran (1989) maintains that the difficulties students experience when learning algebra follow from three areas: (a) the meaning of letters (as variables), (b) new mathematical conventions different from those 
learned in arithmetic, and (c) the movement from a procedural to structural understanding of mathematical expressions.

Recently several educators and researchers have investigated and suggested ways to reform the elementary mathematics curriculum by including generalized presentations of arithmetic that promote algebraic reasoning (e.g., Carpenter \& Levi, 2000; Kaput \& Blanton, 2001; National Council of Teachers of Mathematics (NCTM), 2000). One motivation for these efforts is the judgment that when curricula design incorporates separation of arithmetic and algebra such separation delays children's development of algebraic reasoning and creates difficulties when students are introduced to algebra in middle school and secondary school.

To support the development and growth of children's algebraic reasoning it seems important for both elementary and secondary teachers to be competent in arithmetic and algebraic approaches to problem solving. Moreover, the flexibility to move between arithmetic and algebra is an essential characteristic of problem solving and one that teachers should encourage in students (Sutherland, in press; Van Dooren et al., 2002). As Kieran (1992) states: The challenge to classroom instruction is not only to build upon the arithmetic-to-algebra connection but also to keep alive the algebra-to-arithmetic connection, that is, to develop the abilities to move back and forth between the procedural and structural conceptions and to see the advantages of being able to choose one perspective or the other, depending on the task at hand. (p. 413)

Secondary math teachers especially need to know and understand the mathematical histories of beginning algebra students, and elementary teachers need to have a firm understanding of algebra if they plan to meet the expectations of current curricular reform efforts 
(Van Dooren et al., 2002). There is concern however that many elementary and secondary teachers lack the disposition to move flexibly between arithmetic and algebra, especially in the context of solving word problems. For example, Van Dooren et al. $(2002 ; 2003)$ examined the arithmetic and algebra word problem solving skills and strategy usage of preservice teachers in Belgium, finding that many of the teachers did not possess the knowledge or skills needed to match their strategies to fit the specific characteristics of the word problems; instead, they applied strategies in an almost typical fashion (i.e., elementary teachers used arithmetical strategies; secondary teachers used algebraic strategies). The Van Dooren studies also provided evidence that teachers' content-specific knowledge and skills can affect their appreciation of students' problem solving strategies.

The current study will not examine students' learning of algebra directly, but will investigate preservice teachers who will ultimately support students' transition from arithmetic to algebra. The motivation for investigating teachers is based on the accepted belief that teachers' content knowledge and attitudes influence student learning (Ball \& McDiarmid, 1990; De Corte, Greer \& Verschaffel, 1996; Shulman, 1986; Thompson, 1992; Verschaffel, De Corte, \& Borghart, 1997). Also, judging from the works of several writers it is clear that teaching is thought to be a critical focus of algebra reform (e.g., Carpenter \& Levi, 2000; Conference Board of the Mathematical Sciences (CBMS), 2001; Kaput \& Blanton, 2001; Kieran, 1989, 1992; Nathan \& Koedinger, 2000; NCTM, 2000; Van Dooren et al., 2002; 2003).

The current study invoked the design and methodology of Van Dooren et al. (2002; 2003) to investigate preservice teachers' word problem solving skills and preferred strategies for solving arithmetic and algebra word problems, and it examined the ways in which these factors 
contributed to teachers' appreciation of students' solutions. Moreover, this study extends Van Dooren's line of research by targeting a different population, namely, American preservice teachers, and provided a further investigation of teachers' content-specific attitudes and pedagogical content knowledge through interviews.

\section{Problem Statement And Guiding Questions}

The present study examined and compared the arithmetic and algebraic problem solving skills, strategy preferences, and content-specific attitudes of elementary and secondary preservice teachers. Moreover, this study investigated how greatly these factors influenced a critical aspect of the teachers' future teaching practice, namely, the appreciation of students' arithmetic and algebraic problem solving strategies. Specific attention was also made to evaluate the teachers' ability to apply arithmetic and algebraic strategies in an adaptive or flexible manner.

This research was directed by the following questions: What are the performance patterns and solution preferences between specific subgroups of teachers when asked to solve arithmetic and algebra word problems? Are the teachers able to shift their strategies to fit the specific characteristics of the word problems? What are the appreciation or evaluation patterns between specific subgroups of teachers when asked to consider students' solution strategies from arithmetic and algebra word problems? And what are the teachers' content-specific attitudes towards arithmetical and algebraic problem-solving approaches and strategies?

\section{Background and Rationale}

The work of Van Dooren et al. (2002, 2003), which formed the basis for the current project, was based on an earlier study by Schmidt (as cited in Van Dooren et al., 2002; 2003). Schmidt investigated beginning elementary and secondary teachers from Canadian universities 
and found that many of these teachers could not flexibly switch between arithmetical and algebraic strategies when it was appropriate for the given problem situation, and nearly half of the elementary teachers either could not efficiently apply algebraic strategies or were reluctant to use algebraic strategies when solving problems.

The findings reported by Schmidt were again confirmed when Van Dooren et al. investigated prospective teachers from Belgium. Van Dooren et al. also expanded Schmidt's study in three significant ways. First, they targeted a more varied population that included first year as well as third year teacher trainees. Second, they lengthened the problem sets that were used by Schmidt. And third, they went beyond the scope of Schmidt's investigation by examining relationships between teachers' content knowledge and their didactic behavior. My motivation for replicating and extending the Van Dooren studies was twofold. First, as an educator of teachers, I wondered how American teachers would fare when asked to complete similar tasks as the teachers studied by Van Dooren et al. Considering the results of the Third International Mathematics and Science Study (TIMMS) (Mullis et al., 2000), which sited higher levels of mathematics achievement from Belgium students than students from the United States, I felt that replicating the work of Van Dooren et al. with American teachers would make for a relevant task. Second, I felt that the method used by Van Dooren et al. to define teachers' content-specific attitudes, which consisted of asking teachers to provide brief justifications for their ratings of students' solutions, was somewhat deficient. Thus, I wanted to add a greater qualitative element by incorporating interviews within my investigation.

This study will also further contribute to the literature addressing teachers' mathematical content knowledge. In this domain of research many questions are still unresolved regarding the 
connections between teachers' content knowledge and their teaching practice (Ball et al., 2001). Also, more studies that address the ways teachers interpret and deliver algebra instruction are also needed (Kieran, 1992). On a smaller scale, since all of the teachers who participated in this study are currently or were recently enrolled at Frostburg State University, this work will provide both the Department of Educational Professions and the Department of Mathematics at this institution valuable feedback that could be used for program evaluation or to guide future instructional decisions.

\section{Chapter 2}

\section{Review of the Literature}

\section{Word Problems}

The presentation of word problems is classified into two broad categories according to Reed (1999): elementary and multistep. The first section of this chapter examines relevant research addressing elementary word problems. Then a similar discussion follows for multistep word problems, and, in particular, what is normally referred to as algebra word problems. Even though the current study did not incorporate elementary word problems, a brief survey of some corresponding research issues and findings provides a basis for analyzing multistep problems.

Word problems in general have a well-known reputation in mathematics education, primarily because of the difficulties students encounter when solving such problems. These difficulties are examined through several determinants that include problem classifications, problem characteristics, and solution strategies. Relevant instructional issues and instructional recommendations are also highlighted throughout the presentation. Finally, considering the 
methodology and aim of the current study, a thorough discussion of various cognitive models that attempt to describe the mental processes involved in problem solving is not included.

Elementary problems. Elementary word problems are word problems that require a single arithmetic operation to solve. These problems are first encountered by children in elementary school, and are useful for researchers because they provide a way of understanding children's difficulties when engaged in basic problem solving situations, and because they offer information that may be applied or extended to study more complex, multistep word problems that children will encounter later in their educational careers (Reed, 1999).

Children apply various strategies for solving elementary word problems. Sowder (1988) investigated the strategies of 70 middle school students with considerable experience solving elementary word problems. Some of the documented strategies included, (a) use the operation that was recently discussed in class, (b) guess at the operation to be used, (c) choose the operation that fits the size of the numbers (e.g., divide if the numbers differ greatly), (d) search the problem for key words to determine the operation (e.g., add when "altogether" is found in the problem), and (e) choose the operation that best fits the meaning of the problem.

Although many of the strategies reported by Sowder yielded correct solutions, certain strategies can be problematic. For instance, using key words contained in the problem as cues for identifying the correct operation is a popular strategy that many elementary teachers endorse. However, Nesher and Teubal (1975) have shown examples where the key words can confound the meaning of the problem. For example, consider the following problem, "The milkman brought on Monday 7 bottles of milk. That was 4 bottles less than he brought on Sunday. How many bottles did he bring on Sunday?" The word less usually connotes subtraction; however, in 
this case, addition is the operation that will determine the correct answer. In their study Nesher and Teubal investigated elementary students and found that their performance was more consistent when the key words used in the problem referred to the correct operation.

Using the size of the numbers contained in the problem to determine the operation is another common, but problematic, strategy employed by students for solving elementary problems. This strategy is often founded on fundamental misunderstandings concerning operations (Greer, 1994). For example, Sowder (1988) discovered through interviews that several of his subjects believed "multiplication makes bigger" and "division makes smaller." In one of his studies, Greer (1987) found that the size of the numbers used in the problem greatly affected the operation that was selected to solve the problem. He examined over 100 middle school students of average ability and found that when asked to solve multiplication word problems the type of number used as a multiplier influenced solution performance. When the multiplier was an integer, $92 \%$ of the responses were correct, but when the multiplier was a decimal less than one, $53 \%$ of the responses were correct.

What is clear from the research addressing student strategies is that strategies used by students, while leading to correct solutions, often do not follow from sound mathematical thinking. This conclusion is especially relevant in the domain of elementary problems where the presentations of such problems are often superficial and can lead students to adopt strategies that are limited in applicability (Greer, 1994; Nesher \& Teubal, 1975; Sowder, 1988). Sowder, in particular, blamed the problematic strategies used by his subjects on the "computation-centered" curriculum of elementary schools. And concerning the predominance of the key word strategy, Greer cited a study by Schoenfeld (1982) that reported $97 \%$ of the problems contained in a 
popular elementary textbook series could be correctly solved using the key word strategy.

Current recommendations for elementary school instruction have recognized research on word problem strategies, and have called for a more thorough presentation of word problems (e.g., CBMS, 2001; NCTM, 2000). For example, NCTM's Principles and Standards for School Mathematics encourages teachers to select diverse and worthwhile word problems and to focus instruction on the meaning of operations.

Besides examining the relationships between strategy usage and solution performance another line of research has attempted to analyze solution performance in terms of certain problem features such as semantic structure and verbal complexity. Riley, Greeno, and Heller (1983) summarized the results of several studies that adopted a particular categorization for addition and subtraction problems. The categories, Change, Combine and Compare, were established according to the semantic relations found within the problem. Table 1 contains several examples similar to the ones cited by Riley et al.

With Change problems addition or subtraction is used to cause an increase or decrease in some quantity, and the unknown is the resulting amount, the amount of change, or the starting amount. In Combine problems two given quantities are added or subtracted and the unknown is the combined value, or one of the subsets within the problem. In Compare problems two given quantities are compared through subtraction and the unknown is the difference between the two numbers, the referent, or the compared quantity. The results of this work indicate that both the semantic structure of the word problem and identity of the unknown quantity greatly influenced children's solution performance. Moreover, problems that shared the same operation, but had different semantic structures were consistently found to educe different levels of performance. 
Table 1

Examples of Change, Combine, and Compare Single-step Word Problems

\section{Change problems}

Result unknown: Sara had 4 apples. Then Bill gave her 6 more apples. How many apples does Sara have now?

Change unknown: Sara had 4 apples. Then Bill gave her some more apples. Now Sara has 10 apples. How many apples did Bill give to Sara?

\section{Combine problems}

Combine value unknown: Sara has 4 apples. Bill has 6 apples. How many apples do they have together?

Subset unknown: Sara and Bill have 10 apples altogether. Sara has 4 apples. How many apples does Bill have?

\section{Compare problems}

Difference unknown: Sara has 10 apples. Bill has 6 apples. How many more apples does Sara have than Bill?

Compared quality unknown: Sara has 4 apples. Bill has 6 more apples than Sara. How many apples does Bill have?

Classifying word problems according to children's performance levels says little about why certain problems are more difficult than others. Riley et al. proposed a model to explain these difficulties, which incorporated three main types of knowledge: (a) problem knowledge that allows the problem solver to fit the semantic contents of the problem into a coherent mental 
representation, (b) action knowledge that allows the problem solver to connect the problem representation to his or her known problem solving procedures; and (c) strategic knowledge that allows the problem solver to construct and carry out a sequence of steps. Riley et al. suggested that children's difficulties solving certain problems were due to a deficiency in one or more of these knowledge components.

Another common hypothesis is that children's difficulties are caused by linguistic deficiencies that limit their ability to interpret verbal presentations of word problems (Cummins et al., 1988). Hudson (1983), for instance, demonstrated that the language used to state a word problem could significantly affect solution performance. The young children in his study were shown various drawings depicting pairs of sets whose numerical difference was one, two, or three, and were told that the first set of items represented a collection of birds, and the second, always smaller, set represented a collection of worms. The children were then asked one of two questions: "How many more birds than worms are there?" or "How many birds won't get a worm?" The proportion of correct responses for the first question ranged from $17 \%$ for nursery school children to $64 \%$ for first graders. However, for the latter question the performance ranged from $83 \%$ for nursery school children and $100 \%$ for first graders. A similar study conducted in Belgium by De Corte, Verschaffel, and De Win (1985) demonstrated that rewording word problems to make the semantic relations more explicit could significantly improve solution performance. De Corte et al. incorporated the same classification scheme presented by Riley et al. (1983). For example, a traditional Change/Start Unknown problem might read as follows: "Joe won 3 marbles. Now he has 5 marbles. How many marbles did Joe have in the beginning?" 
According to De Corte et al. the rewording was as follows:

"Joe had some marbles. He won 3 more marbles. Now he has 5 marbles. How many marbles did Joe have in the beginning?"

Out of 173 first and second graders who were asked to solve both the traditional and the reworded problems, 90 students obtained higher scores from the reworded problem set.

Discussing the results of their study, De Corte el al. (1985) affirmed that their findings were consistent with the model proposed by Riley et al. (1983). Recalling the first component of knowledge described by Riley, which was associated with the construction of a mental representation of the problem situation, De Corte et al. concluded that more advanced problem solvers do not rely so much on text-driven processing when constructing problem representations. However, for less advanced problem solvers with limited semantic understanding, verbal statements that make semantic relations more explicit may compensate for this deficiency.

A more demanding set of problems than addition and subtraction problems are multiplication and division word problems. Recall that Greer (1987) found that the type of numbers used in multiplication word problems greatly influenced the difficulty of the problem. Fischbein et al. (1985) also reported similar findings. They presented over 600 students in grades 5, 7 or 9 with various multiplication and division problems; and found that the choice of numbers used in the problem could interfere with the students' ability to choose the correct operation. Attempting to interpret these results Fischbein et al. assumed that arithmetic operations become attached to what they called, primitive intuitive models. Intuitive models are thought to be deeply rooted in the mind of the problem solver, and exert control over his or her 
mental behavior even after the child has been exposed to more formal mathematical notions. Furthermore, the ways in which operations were first learned are thought to contribute to the formation of intuitive models. For example, repeated addition (i.e., $4 \times 3$ means $3+3+3+3$ ) was cited as a primitive model for multiplication. One constraint of this model is that the first number (the operator) must be a whole number. When operators such as 0.32 or $3 / 4$ are used, multiplication, as repeated addition, has no intuitive meaning. Therefore, when problem solvers confront numerical data that violate the constraints of their primitive models, finding a correct solution becomes difficult. Fischbein et al. also made a distinction between intuitive meaning and mathematical meaning. For instance, a child might know $0.32 \times 1.50$ as a valid mathematical expression, but when such an expression is presented in a word problem his or her intuitive model may still dictate the solution process.

Schwartz (1988) presented another explanation for the difficult nature of multiplication and division word problems, which addressed the way operations change the meanings of quantities in mathematical modeling situations. According to Schwartz addition and subtraction are referent preserving operations whereas multiplication and division are referent transforming operations. For example, subtracting 9 dollars from 11 dollars does not change the referent because the resulting quantity still represents a collection of dollars. However, dividing 45 miles by 9 hours results in a referent (miles per hour) that is different from the two given values. Schwartz concluded that the common view that children's early number knowledge eventually leads to a proper understanding of multiplication and division in modeling situations is false. Moreover, she advocated instructional approaches set on making clear distinctions between those operations that preserve referents and those that transform or change referents. 
In sum, it has been shown that children use a variety of different strategies for solving elementary word problems. However, they often adopt strategies that are limited in applicability or are founded on fundamental arithmetic misunderstandings. It was suggested that these outcomes are partly the result of superficial presentations of word problems by both teachers and textbooks. Children's ability to solve elementary word problems may be influenced by both the semantic characteristics and verbal features of problems, and their own conceptual understanding of operations. Riley et al. characterized three types of knowledge required to solve word problems: problem knowledge, action knowledge, and strategic knowledge. An important function of problem knowledge was the construction of a coherent representation of the problem situation. The notion of a problem representation will be mentioned in the next section. Additionally, Riley's classification of elementary word problems (i.e., Change problems, Compare problems, and Combine problems) will also provide a basis for constructing multistep problems.

Multistep problems. Multistep problems are formed by combining two or more of the basic semantic operations associated with elementary word problems (Reed, 1999). For example, consider the following problem:

Charlie has 25 gumdrops. If Charlie gives his brother 7 gumdrops and his sister 14 gumdrops, how many gumdrops must he give to his mother if he wants to give all of the gumdrops away?

The semantic structure of the problem is similar to both a Change problem and a Compare problem. For example, a problem solver may first find the total number of gumdrops given to 
Charlie's brother and sister (Combine problem/combine value unknown). And then subtract the total from 25 gumdrops (Change problem/change unknown).

Sebrechts et al. (1996) highlighted some of the strategies students use to solve multistep word problems. They analyzed the strategies of a diverse group of college students who were asked to solve 20 "algebra" problems, and identified three dominant strategies. The first strategy class included equation-based reasoning where the students attempted to find solutions by using a set of equations, with or without the variables explicitly stated. The second class of strategies contained ratio setups that were characterized by a specific set of equations based on the canonical form $\mathrm{a} / \mathrm{b}=\mathrm{c} / \mathrm{d}$. The third group of strategies contained simulations (often called "guess-and-check") where students modeled the problem situation by assigning different values to one variable until the correct solution was found. Sebrechts et al. also found a number of minor strategies whose purpose was to aid interpretation and support the application of dominant strategies. These minor strategies included restatement of the given information, drawing a picture, statement of known formulae, and verbal descriptions of the problem.

Even though one or more different strategies can be used to solve the same word problem, multistep problems may be classified as either arithmetic or algebraic. What separates these two classes of problems generally has to do with the kinds of strategies used to solve them (Reed, 1999). Although an absolute method for classifying strategies does not exist, a number of studies (e.g., Bednarz \& Janvier, 1993; 1996; Bednarz et al., 1992; Filloy \& Sutherland, 1996; Sebrechts et al., 1996; Van Dooren et al., 2002; 2003) have established consistent distinctions between algebraic and arithmetic strategies. Accordingly, an algebraic strategy is identified by one primary feature, the appearance of at least one equation representing the relations contained 
in the problem including all known and unknown values. This equation-based representation is then manipulated or "solved" to find a solution. An arithmetic strategy, by contrast, does not rely completely on abstract, symbolic representations that are usually associated with algebra; but, rather, on the application of one or more basic arithmetic operations.

Recent studies (e.g., Bednarz \& Janvier, 1993; 1996; Van Dooren, 2002; 2003) have attempted to classify word problems according to the type of strategy that corresponds to the semantic structure of the word problem. Bednarz and Janvier (1993; 1996), in particular, provided a framework for categorizing multistep word problems, which highlighted the semantic structure, and relations between the unknown and known values within a problem. According to this framework arithmetic problems contain relationships between given values that provide a starting state. Moreover, this starting state is what allows a problem solver to apply a sequence of arithmetic operations in order to find a solution. For example, the given values in the problem stated earlier allow a problem solver to first add 7 and 14, and then subtract this sum from 25 . Algebra problems on the other hand do not provide this kind of starting state, and, as a result, the problem solver is often obliged to use an algebraic equation to solve the problem. It should be noted that just because a word problem has an algebraic make-up, doesn't mean that a problem solver must employ an algebraic strategy to find a solution. In many cases a problem solver could still use an arithmetic strategy to solve the problem (MacGregor \& Stacey, 1996).

To distinguish between arithmetic and algebra word problems, consider a revision of the earlier problem:

Charlie has 25 gumdrops. Charlie gave his brother some gumdrops. He gave his sister twice as many gumdrops than his brother and he gave his mother 3 less gumdrops than 
his brother. As a result Charlie has given away all of his gumdrops. How many gumdrops did Charlie give his brother?

The second problem is certainly more complex than the first, but, in particular, the second problem is different in the nature of the given information. To highlight the structural differences between the problems schematization diagrams, which are similar to the ones used by Bednarz and Janvier (1993; 1996), are provided in figure 1. As stated, the first problem provides an arithmetic starting place for finding the solution. However, in the second problem only the relations between the unknown values are given. The problem solver is not provided with an arithmetical starting point, and therefore must assign a value on one of the unknowns or represent the problem with an algebraic equation.

A particular point of concern in the domain of multistep word problems is the transition from arithmetic reasoning to algebraic reasoning. According to Kieran (1992) algebraic reasoning involves symbolizing general numerical relationships and mathematical structures, and operating on these structures. Much of what is learned in solving multistep arithmetic problems does not directly translate to solving algebra problems (Bednarz \& Janvier, 1993; 1996; Bednarz et al., 1992; Reed, 1999). This is partly true because of the noted difficulties students have learning algebra (e.g., Brenner et al., 1997; Davis, 1989; Filloy \& Sutherland, 1996; Herscovics \& Linchevski, 1994; Kieran, 1989; 1992). Algebra word problems, however, present an additional challenge for students, namely, the task of representing problem situations using algebraic equations. This task requires students to understand how letters are used to represent variables and relationships between quantities, and how the equality relation is used to construct an equation (Kieran, 1992; MacGregor \& Stacey, 1996). 
Charlie has 25 gumdrops. If Charlie gives

his brother 7 gumdrops and his sister 14

gumdrops, how many gumdrops must he

give to his mother if he wants to give all of

the gumdrops away?

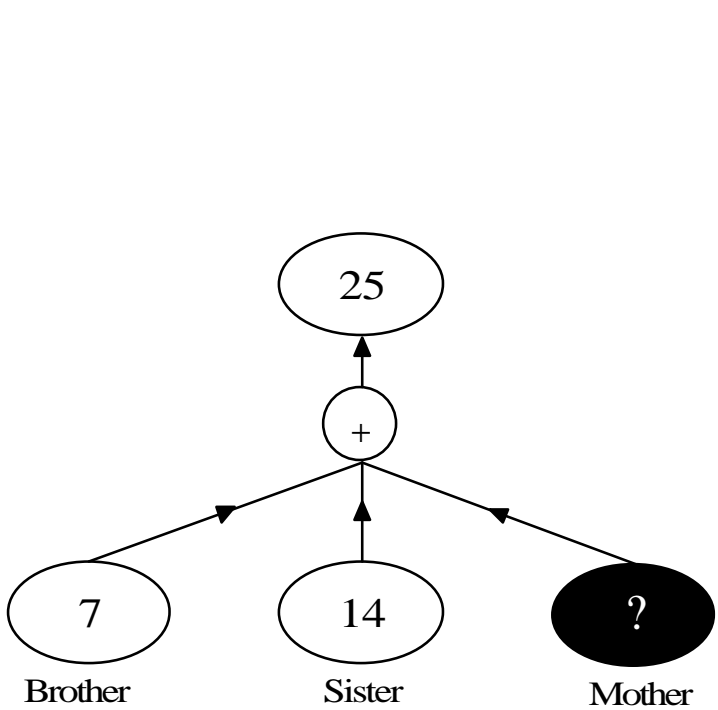

Charlie has 25 gumdrops. Charlie gave his

brother some gumdrops. He gave his sister

twice as many gumdrops than his brother

and he gave his mother 3 less gumdrops

than his brother. As a result Charlie has

given away all of his gumdrops. How many

gumdrops did Charlie give his brother?

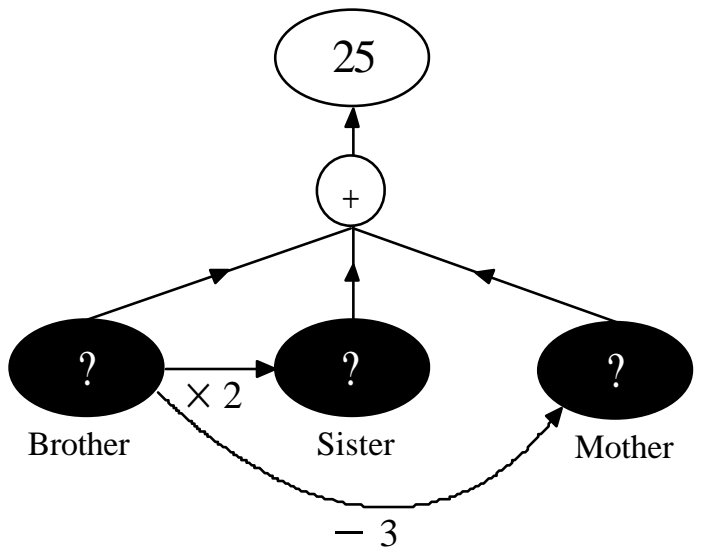

Figure 1. Schematization of word problems according to Bednarz and Janvier (1996).

Note. Black colored ovals represent solutions for the word problems.

The ability to analyze mathematical situations and represent them using algebraic symbols is an important educational standard in mathematics education (NCTM, 2000). 
However, there is evidence that students have difficulty constructing algebraic equations from information presented in algebra word problems. In a study by Clement (1982), 150 freshman engineering majors were ask to use an equation to represent several basic mathematical situations, including the following:

Write an equation using the variables $\mathrm{S}$ and $\mathrm{P}$ to represent the statement: "There are six times as many students as professors at this university." Use $\mathrm{S}$ for the number of students and $\mathrm{P}$ for the number of professors.

Only $63 \%$ of the engineering majors answered this item correctly, and in a sample of 47 nonscience majors taking college algebra only $43 \%$ found the correct algebraic equation. The most common mistake was found to be a reversal error (i.e., $6 \mathrm{~S}=\mathrm{P}$ ). Clement interviewed several of the participants and found two sources for reversal errors, a syntactic word order matching process and a semantic static comparison process. Using the word order matching process participants assumed that the order of the key words in the problem corresponded to the symbols in the equation. Whereas for the static comparison process participants understood that their were more students than professors, however they did not know how to express such a relationship symbolically; and, therefore, placed the multiplier 6 next to the symbol associated with the larger group.

MacGregor and Stacey (1993) conducted a similar study with students ranging from grades 8 to 10 ; however, they used word problems that could be correctly solved using the word order matching process. Of the 281 participants only $27 \%$ could symbolically represent the statement, "s is eight more than t," and only $37 \%$ could represent the statement, "y is eight times the number z." Surprisingly, on average, $46 \%$ of the incorrect responses were reversal errors 
such as " $\mathrm{s}+8=\mathrm{t}$ " and " $8 \mathrm{y}=\mathrm{z}$." These results suggest that reversal errors do not necessarily result from substituting key words with symbols sequentially as explained by Clement (1982). MacGregor and Stacey offered another explanation, namely, that rules of natural language might interfere with the process of translating a mathematical relation into an algebraic equation. For example, in the statement, "y is eight times the number z," if the letters, "y" and " $z$ " are thought of as nouns and the number " 8 " as an adjective, then it is conceivable for a problem solver who holds such a perspective to represent the problem situation as " $8 \mathrm{y}=\mathrm{z}$."

The failure to accurately construct equation-based representations from algebra word problems may be thought to result from linguistic comprehension errors. A later study by MacGregor and Stacey (1996) showed that a majority (70\%) of the sampled students who were incapable of formulating correct equations from algebra word problems could still solve the problems using arithmetic strategies. Comprehending the problem was not an issue for these students; rather, their difficulties resulted from misuses of algebraic notation and their own inabilities with forming equations. Similarly, Sebrechts et al. (1996) found linguistic factors to have only a minimal effect on students' ability to construct equation-based representations of word problems. Instead, the complexity of relations between problem elements was found to have the greatest influence over students' ability to construct equations.

Although students are taught to solve algebra word problems by formulating and solving algebraic equations, they continue to rely on non-algebraic strategies. This is especially true for beginning algebra students who lack adequate knowledge needed to support the formulation of algebraic strategies (MacGregor \& Stacey, 1996; Reed, 1999). Experienced problem solvers also tend to use non-algebraic strategies when solving algebra word problems (Hall et al., 1989). 
One explanation for why this occurs calls into question the conceptual knowledge base of the problem solver. According to Hatano (1988) experience in solving mathematical problems can be thought of as a process of acquiring expertise. Even though problem solvers have acquired expertise within a certain problem domain, they may still be unable to solve, or efficiently solve, specific types of problems within that domain.

Hatano made a distinction between what he called routine expertise and adaptive expertise. The key difference between problem solvers who have acquired routine expertise and those who have acquired adaptive expertise is the level of flexibility in their problem solving methods. Because of their problem solving experiences, routine problem solvers have attained a set of procedures and actions that make them successful when solving familiar types of problems. However, when they are confronted with unfamiliar problem situations, routine problem solvers rely on well-practiced strategies or make minor modifications to these strategies through a process of trial and error. Adaptive problem solvers on the other hand possess a rich conceptual knowledge base that allows them to validate conventional solution strategies and make variations to known procedures according to the changes in constraints of the problem. Because of their conceptual knowledge, adaptive problem solvers find meaning in each step of a procedure, and this in turn allows them to solve novel problems in a more efficient and flexible manner.

Developing in students an adaptive approach to problem solving is considered an important educational goal. According to NCTM (2000) Standards, by the time students enter high school they "should have access to a wide range of strategies, be able to decide which ones to use, and be able to adapt and invent strategies" (p.54). A long standing instructional concern 
has made note of the superficial presentations of word problems and word problem strategies by both teachers and textbooks, and the effect of such presentations on students' problem solving abilities (This point was discussed in the previous section). Traditionally, mathematics instruction has focused on matching specific classes of word problems to specific strategies (Mayer, 1981; Reed, 1999; Schoenfeld, 1992). From this perspective word problem strategies can be seen as "recipes" to be used after specific problem characteristics have been identified. Problem categorization is a valuable skill, because it helps students organize their knowledge by identifying specific word problems with specific strategies; however, when used to narrowly, it can potentially limit the transfer of knowledge and skills across different classes of problems (Price \& Driscoll, 1997; Reed, 1999; Sebrechts et al, 1996).

Recently, Van Dooren et al. (2003) raised a similar issue in discussing the implications of a study that found the problem solving behaviors of prospective teachers to be inflexible. Van Dooren et al. based their investigation on an earlier study by Schmidt (as cited in Van Dooren et al., 2002; 2003) that investigated the strategy preferences of a group of first year teacher trainees in Canada. Van Dooren et al. extended Schmidt's work in part by targeting a population of future elementary and secondary teachers in Belgium, who were either in the first or third year of teacher training. The teachers were asked to solve a collection of arithmetic and algebra word problems that were classified according to Bednarz and Janvier's classification scheme. Van Dooren's finding were very similar to those reported by Schmidt: nearly all of the secondary teachers applied algebraic strategies even in situations where arithmetic strategies were more direct and efficient. And only about half of the elementary teachers consistently demonstrated flexibility when solving the word problems. The other group of elementary teachers could not 
effectively solve the more difficult algebra word problems because of their strong preference for arithmetic strategies. Surprisingly, the strategy preferences of third year trainees were comparable to those of first year trainees. That is, many of the teachers with three years of training still demonstrated the same "routine" problem solving behaviors as first year teacher trainees.

The work of both Van Dooren et al. and Schmidt suggests that the narrow focus of some teacher training programs may foster limited and inflexible strategy preferences in teachers. Moreover, the effects of such programs could inadequately provide teachers with the knowledge needed to develop adaptive problem solving behaviors in students and could inevitably compromise teachers' ability to support students' transition from arithmetic to algebra.

\section{Summary}

The basic operations and semantic structures associated with elementary problems can be combined in various ways to form multistep word problems. Students have been shown to apply various strategies when solving multistep problems. These strategies include performing simulations, forming and solving equations, and applying arithmetic operations. Additionally, students often employ "helper" strategies, such as drawing a diagram or restating given problem information, in order to facilitate problem interpretation and support primary strategies.

Distinctions have been made between arithmetic and algebraic strategies. Arithmetic strategies are thought to contain multiple calculations taken from basic arithmetic operations, rather than explicit equation based representations that are associated with algebraic strategies. Similarly, based on semantic considerations, multistep problems may be classified as either arithmetic or algebraic. According to the classifications provided by Bednarz and Janvier (1993; 
1996) arithmetic word problems provide a starting state, which allows a problem solver to employ a sequence of arithmetic operations in the process of finding a solution. Algebraic problems on the other hand do not provide such a starting state and in many cases a problem solver is forced to use an equation-based representation to efficiently solve the problem.

The introduction of algebra marks a problematic transition for students that extends beyond arithmetic reasoning, and involves generalizing numerical relationships and operating on symbolic structures. Constructing equation-based representations is thought to be a challenging aspect of solving algebra word problems. Students often make reversal errors when asked to write algebraic equations from simple statements, and they frequently use non-algebraic strategies to avoid equation-based representations. Comprehension errors made from solving algebra word problems were shown to be dependent on the semantic complexity of problems and students' own understanding of symbolic notation. Thus, linguistic factors played a lesser role in affecting problem comprehension of algebra problems.

Typically students are taught to solve algebra problems by forming and solving equation based representations. Beginning algebra students often use non-algebraic strategies as a way to compensate for their lack of algebraic reasoning. Experienced problems solvers were also found to rely on non-algebraic strategies while solving algebra word problems. One explanation for the latter case suggests that some advanced problem solvers possess only "routine expertise," i.e., they lack the conceptual knowledge that allows them to validate appropriate strategies and to construct variations of familiar strategies.

As a goal of high school instruction, NCTM cites developing in students a disposition to flexibly apply and invent strategies in a manner that is appropriate with the constraints of the 
problem. There is concern that superficial presentations of word problems and word problem strategies by both teachers and textbooks may limit students' problem solving behavior. In particular, the tendency for textbooks to classify specific types of word problems with specific types of strategies may compromise students' ability to apply strategies in a flexible manner. A study by Van Dooren et al. (2003), which found the strategies preferences of prospective teachers to be stereotypical, provided evidence that the effects of narrow presentations of word problems may compromise the quality of some teacher education programs.

\section{Preservice Teachers' Content Knowledge}

The current study investigated the mathematical content knowledge of prospective teachers by examining teachers' arithmetic and algebraic word problem strategies, their ratings of student strategies, and their justifications of these ratings. Several of the teachers were also interviewed to probe their general attitudes towards arithmetic and algebraic problem solving methods. While completing these tasks, teachers relied not only on their knowledge of mathematics, but also on their personal experiences as mathematics students, and their understanding of pedagogy. Moreover, these tasks touched upon two interrelated components of the teachers' content knowledge: subject matter knowledge and pedagogical content knowledge (Ball, 1988; Shulman, 1986; Van Dooren et al., 2002; 2003). For organizational purposes, each of these components is discussed separately, and specific attention is given to a second study by Van Dooren (2002) that provided a foundation for the current study.

Subject matter knowledge. Mathematical subject matter knowledge generally refers to knowledge of the concepts, the propositions, and the definitions that constitute the discipline of mathematics. However, by considering subject matter knowledge in the context of teaching, 
researchers (e.g., Ball, 1988; Ball \& McDiarmid, 1990; Even, 1993; Leinhardt \& Smith, 1985; Shulman, 1986; 1987) have expanded their views of subject matter knowledge and, consequently, have come to see it as a multidimensional construct. For example, according to Ball and McDiarmid (1990, p. 440) subject matter knowledge goes beyond knowledge of mathematics per se (i.e., substantive knowledge), and includes knowledge involved in validating various mathematical perspectives, and understanding the connections between those perspectives. It also includes affective aspects of teachers' knowledge such as their acquired preferences for particular topics or activities as well as their tendencies to pursue certain methods and avoid others.

Both teacher educators and researchers (e.g., Ball, 1988; CBMS, 2001; Grossman et al., 1989; Ma, 1999; NCTM, 2000) have acknowledged the significance of mathematical subject matter knowledge for the education of teachers. For example, in their general recommendations for the education of prospective teachers, CBMS (2001, p. 7) affirms the importance of a thorough understanding of the mathematics teachers are expected to teach, of learning interconnections among the various procedures and applications, and of recognizing both the sources of student errors and students' understanding of the mathematics being taught. Current recommendations for school mathematics such as those posed by NCTM have also placed a higher demand on teachers' subject matter knowledge. For example, in their vision statement $\operatorname{NCTM}(2000$, p. 3) promotes a form of mathematics instruction where exploration and discovery is encouraged and is accomplished through several important classroom tasks some of which include approaching problems from multiple perspectives, validating conjectures through 
reasoning and proof techniques, and communicating mathematical ideas both orally and in writing.

Today there is concern that current reforms for school mathematics may present a challenge for new teachers, especially those who have learned mathematics in a traditional setting where the teacher and textbook were assumed the primary conveyors of mathematical knowledge (Ma, 1999; Simon \& Blume, 1996). It has been shown that teachers with strong subject matter preparation are more likely to reveal connections among mathematical ideas, to be flexible in their teaching, and use more conceptual explanations in the classroom (Brown \& Borko, 1992; Grossman et al., 1989; Leinhardt \& Smith, 1985; Ma, 1999). The assertion that teachers' subject matter knowledge affects classroom instruction and what students ultimately learn has been strongly established (Fennema \& Franke, 1992). However, as Ball et al. (2001) point out, the empirical support for this assertion has eluded researchers, because no overall consensus exists on the mathematical knowledge that is required to teach.

In the past both policy makers and researchers believed that substantive knowledge of a mathematics was all that was required to teach (Grossman et al., 1989). Early research addressing teachers' content knowledge, for instance, attempted to find empirical evidence for relationships between teachers' subject matter knowledge and student achievement by identifying teachers' knowledge with measures such as total number of courses taken, grade point averages, and standardized tests scores (Ball et al., 2001; Grossman et al., 1989). Unfortunately many of these studies failed to show strong relationships between subject matter knowledge and student achievement, and, as a result, it was thought that subject matter 
knowledge was badly conceptualized (Grossman et al., 1989). This result, in part, led researchers to expand their views of subject matter knowledge.

Recent research with similar aims as the current study has attempted to investigate teachers' subject matter knowledge with more of a qualitative focus on teachers' understanding of specific mathematical concepts and ideas (Ball et al., 2001). Overall the general findings from this body of work indicate that both elementary and secondary teachers hold fundamental misunderstandings of basic mathematical concepts and relationships. Several studies (e.g., Ball, 1988; 1990; Graeber, Tirosh, \& Glover, 1998; Leinhardt \& Smith, 1985; Ma, 1999; Simon, 1993; Thipkong, \& Davis, 1991) have examined elementary teachers and found weaknesses in their conceptual understanding and application of basic concepts such as operations, fractions and decimals. For example, Leinhardt and Smith used interviews and observations of teaching lessons to investigate expert and novice elementary teachers. They found that expert teachers used more conceptual information in their lessons and made more connections between topics than novice teachers. And they also noted considerable differences in knowledge of basic fractions concepts between novice and expert teachers. Graeber, Tirosh, and Glover examined prospective elementary teachers' knowledge of multiplication and division and found that many of the teachers held misconceptions about these operations. Ma's comparison study of American and Chinese elementary teachers found that American teachers' knowledge of basic mathematics was procedurally driven and highly fragmented, and they had difficulty providing explanations of basic algorithms associated with multiplication and division. In one of her investigations, for instance, Ma noted that only one out of the 23 American teachers she interviewed could generate an appropriate example problem for division by a fraction. 
Much of the work addressing teachers' subject matter knowledge has tended to focus on elementary teachers, because researchers believed, initially at least, that secondary teachers, who are usually required to major in mathematics, did not hold the same misconceptions as their elementary teachers (Ball et al., 2001). While secondary teachers have been shown to outperform their elementary counterparts on problem solving tasks, several studies (e.g., Ball, 1988; 1990; Even, 1993; Van Dooren et al., 2003; Wilson, 1994) have revealed deeper weaknesses in the subject matter knowledge of secondary teachers. For instance, Even (1993) used a combination of interviews and questionnaires to examine prospective secondary teachers' understanding of functions and found that many of the secondary teachers had a narrow understanding of this concept. Ball (1990) interviewed prospective elementary and secondary teachers and, similar to Ma's results, found their knowledge of division was based more on memorization than on conceptual understanding, and their overall substantive knowledge was founded on rules and was highly compartmentalized. A study by Van Dooren et al. (2003), which was discussed in the previous section, found that when asked to solve arithmetic and algebra word problems, prospective teachers tended to apply strategies that were typical of their teaching level.

Besides substantive knowledge, teachers must rely on other forms of knowledge when teaching mathematics (Ball, 1988; Ball \& McDiarmid, 1990; Ma, 1999; Shulman, 1986; 1987; Simon \& Blume, 1996). For example, teachers' understandings and attitudes about mathematical knowledge, where it comes from and how it is established, influences a number of classroom actions, especially the ways teachers respond to student questions (Ball, 1988).

Studies (e.g., Ball, 1988; Ma, 1999; Simon \& Blume, 1996) have shown that when it comes to 
verifying conjectures and establishing mathematical truths prospective teachers can often provide only partial arguments. For instance, when asked to respond to a student conjecture that was accompanied by a verifying example, the prospective teachers in Ball's study were unaware that a finite number of examples were insufficient to prove the conjecture. The same outcome was noted in Ma's sample of US teachers, when she presented them with a similar task. Simon and Blume investigated several preservice teachers enrolled in a mathematics content course, and documented their social interactions. They noted that the teachers initially did not question the validity of explanations provided by their peers. However, when questioning the work of their classmates, similar to the findings of Ball and Ma, many of the teachers accepted inductive evidence as valid mathematical justification.

Questions such as "What are the sources of mathematical knowledge?" and "What does it mean to do mathematics?" were further explored by Ball (1988). Many of the teachers in Ball's sample held the view that mathematics consisted of a collection of facts, rules and procedures. This outcome was most noted in secondary teachers who believed that stating rules, definitions and procedures was synonymous with teaching mathematics. In another task Ball questioned teachers as they sampled specific problems, some of which were solved using nonstandard solution strategies. In their responses, the teachers emphasized the importance of learning standard problem solving procedures, and many said they would discourage the use of studentinvented algorithms in their classrooms.

The belief that mathematics is a fixed body of knowledge consisting of rules, procedures and definitions also influenced teachers' understanding of what it means to do mathematics. For example, Ball asked teachers to describe the characteristics of a person whom they believed was 
good at mathematics. Ball found that teachers held one of two general views. The first view centered on remembering, that is, being good at mathematics was equated with remembering formulas, rules and procedures with the aim of finding the correct answer. The second view had more of a problem solving orientation, and included characteristics like being able to apply an algorithm in a step-by-step manner, or having the ability to consider alternatives. This latter perspective was also noted by Michael (2002), when he asked a group of prospective elementary teachers to describe the characteristics of a "good" problem solving strategy. Michael found that the majority of teachers viewed problem solving in terms of specific steps such as "Write down all information" or "Check work" without considering the quality of mathematics that would be produced from the solution process itself.

The works sited here seem to paint a rather bleak picture of prospective teachers' subject matter knowledge. In should be noted, however, that because they describe teachers' knowledge more than teaching itself, these studies still do not accurately define the knowledge needed for effective teaching (Ball et al., 2001). While the current study did not attempt to address this question, it did, however, examine one aspect of prospective teachers future practice, namely, the evaluation and appreciation of students' problem solving strategies. The next section examines a second aspect of teachers' content knowledge that is unique to the profession of teaching, and includes a number of studies that looked at teaching more closely.

Pedagogical content knowledge. The notion of pedagogical content knowledge was first introduced by Shulman (1986) to help better conceptualize the ways knowledge was used in the teaching of mathematics. According to Shulman pedagogical content knowledge involves "the ways of representing and formulating the subject that make it comprehensible to others" (p. 9). 
While related to subject matter knowledge, pedagogical content knowledge addresses more deeply the connections between content and pedagogy, and is a form of knowledge that a student, or a mathematician, would not necessarily possess as a result of studying mathematics alone (Brown \& Borko, 1992; Ball et al., 2001). Some examples of pedagogical content knowledge include knowing particular topics or procedures that students routinely find difficult, knowing various ways to represent a concept within a lesson, or understanding students' use of knowledge and common errors (Ball, 1988; Graeber, 1999; Shulman, 1986; 1987; Wilson, Shulman \& Richert, 1987).

The notion of pedagogical content knowledge has impacted the ways both researchers and teacher educators look at teachers' content knowledge. For instance, it implies that teachers not only need to know content deeply, but also need to know and understand how students think about and respond to various topics (Ball et al., 2001). It has been found that experienced teachers generally exhibit more pedagogical content knowledge than both beginning and prospective teachers (Borko et al., 1992; Borko \& Livingston, 1989; Leinhardt \& Smith, 1985; Livingston \& Borko, 1990). Practicing teachers are believed to acquire pedagogical content knowledge through a number of activities and situations including learning from both colleagues and students, intensely studying teaching materials, and teaching the same topics again and again over time (Ball et al., 2001; Ma, 1999).

Current recommendations for teacher education such as those posed by NCTM and CBMS, and the findings of several comprehensive studies (e.g., Ball, 1988; Carpenter et al., 1989; Fennema et al., 1996, Ma, 1999), cite the importance of and the need for developing prospective teachers' pedagogical content knowledge, especially teachers' knowledge of 
students' thinking and students' problem solving approaches. In her discussion of the "Big Ideas" that should be included in every teacher education program, Anna Graeber (1999) emphasized the need for prospective teachers to be skillful in recognizing what students understand. Without this attention to understanding their students, according to Graeber (p.193), teachers will not be able to accurately assess understanding or use knowledge of their students' understanding to make proper instructional decisions.

The work of Ball (1988) and Ma (1999), which was mentioned in the previous section, examined teachers' understanding of students' knowledge by looking at how teachers respond to conjectures and non-standard algorithms. Other studies, which will support the current project more directly, have focused on the ways teachers' evaluate various problem solving strategies. For example, Michael (2002) asked prospective elementary teachers to solve a collection of problems using as many strategies as they could manage. Teachers were then asked to choose their "best" strategy and justify their choice. Michael found that teachers generally favored algebraic strategies, and their justifications, while vague at times, seemed to reflect their preference for strategies that were easy to apply and easy to understand.

A study by Van Dooren et al., (2002), presented elementary and secondary teachers with three solution strategies, one algebraic and two arithmetical, for several algebra and arithmetic word problems. Teachers were asked to rate each solution and provide a brief justification for each of their highest ranked solutions. Van Dooren et al. also examined relationships between teachers' subject matter knowledge and their pedagogical content knowledge by looking at the interactions between teachers' own problem solving preferences and their ratings of students' solution strategies. The overall findings cited a positive correlation between teachers' strategy 
preferences and their solution ratings. That is, teachers were found to give higher ratings to those solutions that they themselves used when solving the word problems. When Van Dooren et al. examined the responses from each group of teachers they found that elementary teachers showed more variety in their ratings than their secondary counterparts. For example, while both groups of teachers showed an appreciation for algebraic strategies when used to solve algebra problems, the elementary teachers demonstrated a greater appreciation for arithmetic strategies than the secondary teachers. This outcome was further supported by the elementary teachers reliance on arithmetic strategies for solving word problems (Van Dooren et al., 2003). An analysis of the teachers' justifications also showed that elementary teachers frequently gave higher ratings to those strategies that were thought to be simple and appropriate to the problem. The secondary teachers on the other hand cited the superiority of the algebraic solution and consequently rated this solution higher regardless of the problem context. One important implication of the work of Van Dooren et al. (2002) suggests that teachers' appreciation of students' solution strategies is influenced by their own problem solving preferences.

\section{Summary}

Early views concerning teachers' content knowledge were founded on the belief that substantive understanding of mathematics was all that was needed to teach mathematics. Much of the research from this era failed to show significant relationships between teachers' subject matter knowledge and student achievement. The shortcomings of this work led researchers to broaden their views of content knowledge in two important ways. First, teachers' subject matter knowledge was expanded to include other ways of knowing that went beyond the bounds of substantive knowledge. This included knowledge needed to validate mathematical perspectives 
or to represent connections between various mathematical topics. It also included affective aspects of teachers' knowledge such as their preferences for certain topics or certain problem solving methods.

Another important idea that resulted from this early research was Shulman's (1986) notion of pedagogical content knowledge. Pedagogical content knowledge established a link between teachers' knowledge of content and their knowledge of pedagogy, and it implied that teachers need to have a deep understanding of subject matter as well as an understanding of students' use of knowledge. Some examples of pedagogical content knowledge include understanding aspects of a mathematical idea that students find difficult, knowing how to represent concepts to make them more comprehensible, and knowing how students use and interpret knowledge.

Current mathematics reformists support a form of instruction that is in sharp contrast with the traditional model where the teacher and textbook were the primary sources of knowledge. These authors encourage classroom activities that provide students with opportunities to investigate, discover and communicate mathematics. Recommendations for teacher education programs emphasize the development of teachers' subject matter knowledge as well as their pedagogical content knowledge. Not only are today's teachers expected to know mathematics deeply, they are also expected to make connections between various concepts, use multiple approaches to problems, and understand the sources of student errors.

It has been established that teachers with strong subject matter preparation are more likely to make connections among mathematical ideas and use more conceptual explanations in the classroom. And it is a widely held belief that teachers' subject matter knowledge is an 
essential determinant of student learning. Research has shown that experienced teachers generally exhibit more pedagogical content knowledge than beginning teachers. And several comprehensive studies cited the value of developing prospective teachers' pedagogical content knowledge.

Recent work that addressed prospective teachers' subject matter knowledge adopted qualitative methodologies to investigate teachers' understanding of specific topics, their views regarding mathematical knowledge, and their content specific attitudes. The general findings from this body of work suggest that preservice teachers' substantive understanding of mathematics is procedurally driven and highly fragmented. Furthermore, both beginning elementary and secondary teachers were found to hold fundamental misunderstanding of basic mathematical concepts. Other studies sited here showed that prospective teachers often accept inductive evidence as valid justification when responding to student conjectures. Prospective teachers' views about the ways mathematical knowledge is established and derived were also found to shape their attitudes towards teaching and doing mathematics.

Studies that examined connections between pedagogical content knowledge and prospective teachers' appreciation of word problem strategies were also cited. It has been show that preservice teachers generally prefer solution strategies that are thought to be simple and easy to apply, and in some cases these judgments were made without considering the mathematical relevance of a particular strategy. The work of Van Dooren et al. (2002) provided evidence that teachers' appreciation of students' solution strategies are influenced by their own preferred problem solving methods, and the elementary teachers in their sample were shown to appreciate a wider variety of strategies than their secondary counterparts. 


\section{Chapter 3}

\section{Method}

From a methodological perspective the present study differed from the Van Dooren studies in two distinct ways. First, the participants were not classified according to the number of years of teacher training. Recall that Van Dooren and his colleagues investigated prospective teachers who were either in the first or third year of training. It was found that differences in year of training did not have a significant comparative effect on the participants' spontaneous strategy use. Because of this finding, and the logistical difficulties associated with obtaining a balanced sample of preservice teachers with two distinct levels of training, the present study only required that each participant completed at least one full semester of course work as an elementary or secondary education major. Second, considering the sample size and sample characteristics, I was forced to simplify the analysis. For instance, Van Dooren and his colleagues used three-way and four-way analysis of variance (ANOVA) with two betweensubjects independent variables. However, in the present study, two-way and three-way ANOVA tests were employed each with one between-subjects independent variable. Besides wanting to maintain the methodology of Van Dooren et al., I chose to use ANOVA as the primary method for analyzing the data, because it is viewed as a robust test (see Howell, 2002, p. 340) that produces accurate results in spite of violations to population assumptions (e.g., normality and homogeneity of variance).

\section{Participants}

The participants were elementary and secondary education majors enrolled at Frostburg State University (FSU), a small liberal arts university located in western Maryland. Elementary 
education majors at FSU are trained in language arts, mathematics, reading, science, and social studies, and are required to choose an area of specialization consisting of 24 credit hours. Students training to become secondary teachers at FSU are required to major in a content area such as mathematics, history, chemistry, etc.

Participants were initially solicited through mathematics courses. I met with four sections of students enrolled in Problem Solving for Elementary Teachers II to obtain elementary participants. From these meetings three students volunteered. I also found six secondary participants who were all taking a history of mathematics course. The remainder of the elementary participants was obtained through mass email solicitations. Because of the scarcity of students training to become secondary mathematics teachers at FSU, I was forced to email several recent graduates who were all working in the county as either regular or long-term substitute teachers. The remaining secondary participants came from this group of recent graduates.

Nine of the elementary teachers were specializing in mathematics, and one was studying science. Moreover, all of the elementary teachers successfully completed Problem Solving for Elementary Teachers I (Math 206). Math 206 was chosen as a reference course because it provided the elementary participants with a variety of experiences applying problem-solving strategies over several problem contexts including arithmetic and algebra word problems. As stated, all of the participants at the secondary level were mathematics majors.

Table 2 shows the gender make-up of the sample. All 20 of the participants were Caucasians, and 19 were between the age of 18 and 24 years. One of the secondary participants 
was in her early thirties. Out of the 20 participants, six (three from each teaching level) were selected for interviews. The six interviewees were selected evenly by gender.

Table 2

Gender Composition of Sample

Males Females Total

$\begin{array}{llll}\text { Elementary } & 2 & 8 & 10\end{array}$

$\begin{array}{llll}\text { Secondary } & 5 & 5 & 10\end{array}$

$\begin{array}{lll}\text { Total } & 7 & 13\end{array}$

\section{Research Questions}

Question one. Does Teaching Level (between-subjects independent variable, elementary versus secondary) or Problem Type (within-subjects independent variable, arithmetic versus algebra) yield a significant $(p<0.05$ ) difference on (1) Problem Test Score (dependent variable) and (2) Problem Solution Agreement (dependent variable)?

Question two. Does Teaching Level (between-subjects independent variable, elementary versus secondary) or Problem Type (within-subjects independent variable, arithmetic versus algebra) or Strategy Type (within-subjects independent variable, algebraic versus manipulatingthe-structure versus generating numbers/guess-and-check) yield a significant ( $p<0.05)$ difference on Evaluation Score (dependent variable)? 
Question three. Do the participants' preferred strategies for solving arithmetic and algebra word problems influence their appreciation of students' solutions to similar types of word problems?

Question four. What are the participants' content-specific attitudes towards arithmetic and algebra word problem solving, and do these attitudes depend on factors such as Teaching Level?

Independent Variables

Teaching level. The particular school branch for which a participant was studying determined his or her teaching level. The choice for two levels, elementary and secondary, was based on the methodology of Van Dooren et al. (2002; 2003).

Problem type. Two classes of word problems were used, arithmetic and algebra, in the questionnaires. The problems were divided equally over the three semantic categories used by Van Dooren et al. (2002; 2003): unequal sharing, transformation, and relation between quantities. Figures 2 through 4 provide examples of arithmetic and algebra word problems that were used in the study along with corresponding schematization diagrams for each problem. The semantic categories highlight the complexity and involved relations of word problems found in a variety of arithmetic and algebra textbooks (Bednarz and Janvier, 1993; 1996), and are used here to contrast the structural and relational differences between the various semantic categories.

Although a strategy used to solve a word problem does not necessarily have to correspond to a particular problem classification scheme, the particular mathematical classifications used here provided a practical way to highlight the most efficient solution strategy based on the given structure of the word problem, and the one most likely to be used by an expert 
Arithmetic Problem

Algebra Problem

Participants in a timed fishing contest were competing for the largest total catch. The contestants were only allowed to count carp, bass and catfish. Three times as many carp were caught than catfish. And 16 more bass were caught than carp. If 34 bass were caught out of 58 fish, how many carp and catfish each were caught?

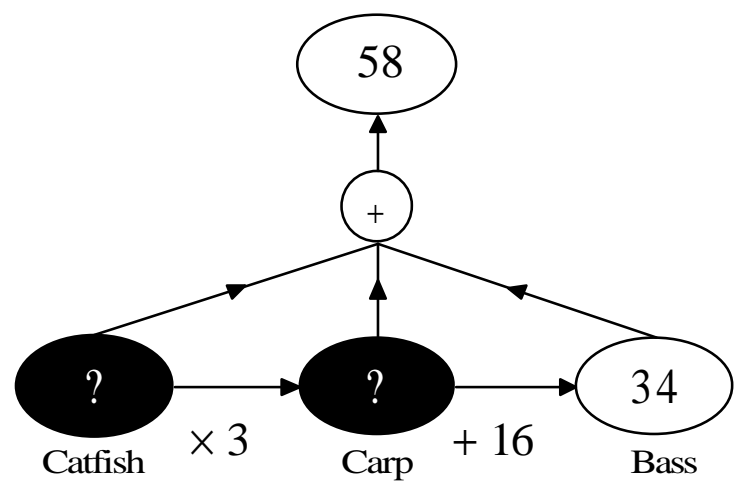

A car dealership sold 16 cars in one month.

There were 2 times as many vans sold than sedans and 4 less sedans than trucks. How many vans, sedans and trucks each were sold?

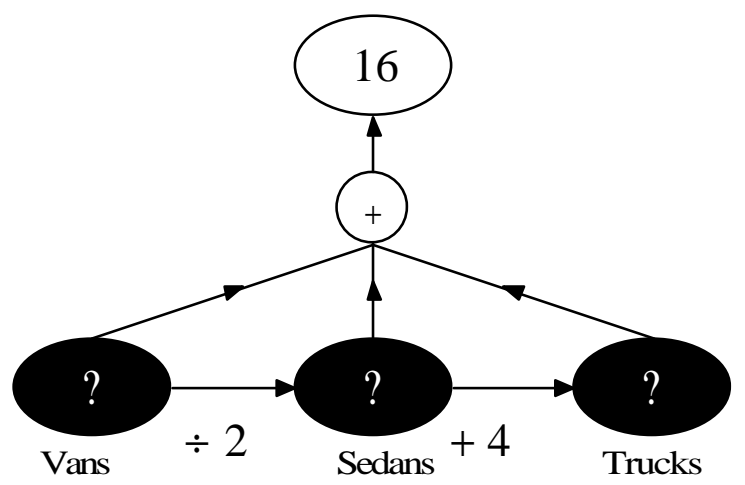

Figure 2. Schematization of an arithmetic and algebra word problem from the "unequal sharing" semantic category. Note. Black colored ovals represent solutions for the word problems. 
In 5 years Mrs. Patrick will have taught school three times longer as Mr. Wilson will have then. If Mrs. Patrick has been teaching for 13 years, how long has Mr. Wilson been teaching?
Last week Melody sold 20 less boxes of cookies than her sister. This week Melody's sister sold 7 boxes while Melody sold twice as many as last week. As a result, Melody has now sold 17 boxes less than her sister. How many boxes of cookies did Melody sell last week?

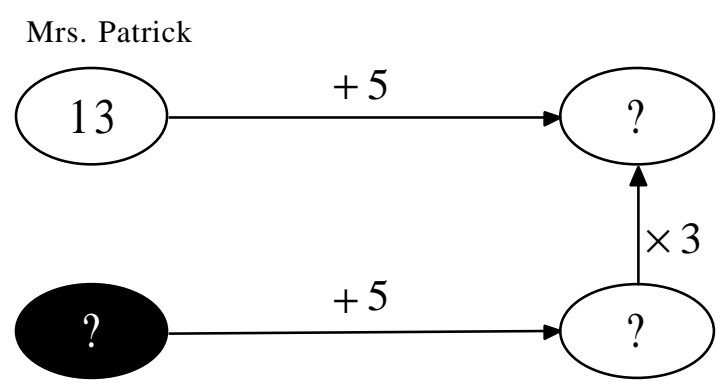

Mr. Wilson

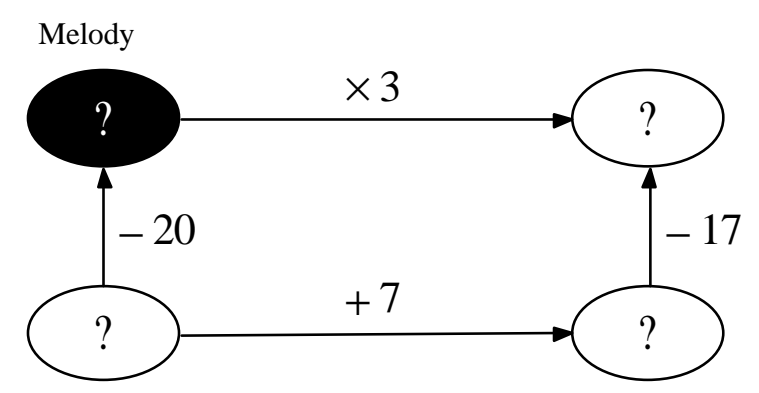

Melody's Sister

Figure 3. Schematization of an arithmetic and algebra word problem from the "transformation" semantic category.

Note. Black colored ovals represent solutions for the word problems. 
A small online shirt business sells both short sleeve and long sleeve shirts. Last month the business brought in $\$ 616$ in sales. That month 11 long sleeve shirts were sold at \$20 per shirt. If the price for a short sleeve shirt was $\$ 8$ less than a long sleeve shirt, how many short sleeve shirts were sold?

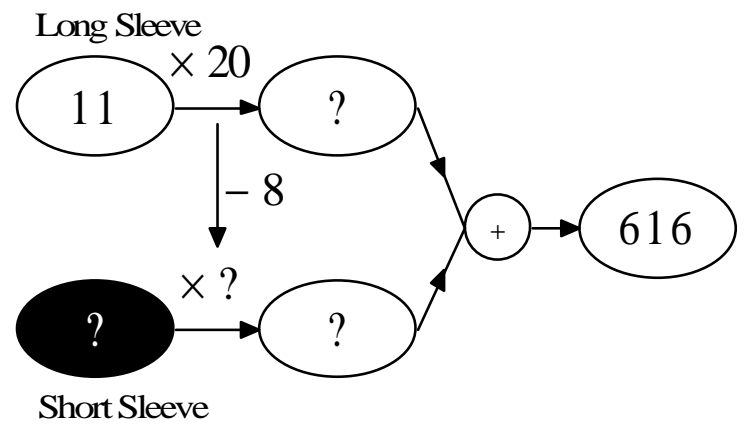

The opening night of a musical generated $\$ 912$ in ticket sales. The price for an adult ticket was $\$ 15$ and a child ticket sold for $\$ 8$.

If there were twice as many adults than children, how many adults attended the musical? How many children attended the musical?

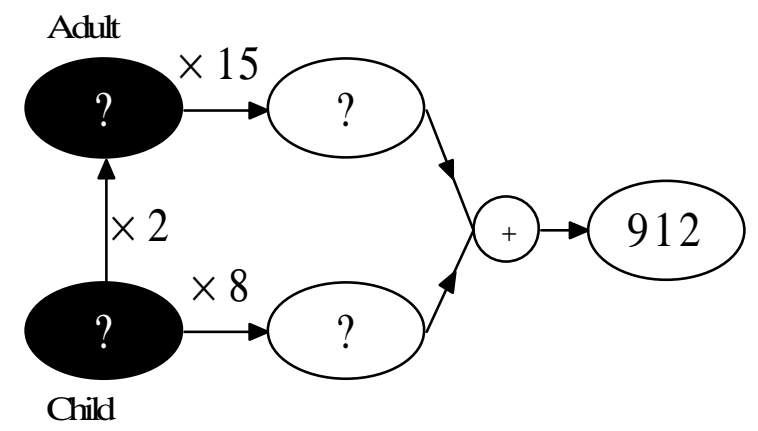

Figure 4. Schematization of an arithmetic and algebra word problem from the "relation between quantities" semantic category.

Note. Black colored ovals represent solutions for the word problems.

problem solver (Van Dooren et al., 2002). From this point of view, the type of solution strategy a problem is most likely to induce determines the classification of that problem. For instance, consider the unequal sharing problems in Figure 2; the arithmetic problem provides a starting 
state (Bednarz and Janvier, 1993; 1996), which allows the problem solver to apply a series of arithmetic operations to find the solution (Filloy \& Sutherland, 1996; Herscovics \& Linchevski, 1994; Kieran, 1992; Van Dooren et al., 2002; 2003). However, for the algebra problem with similar semantic structure, this method is impossible because the problem offers no starting state.

Strategy type. Participants' solution strategies were identified according to a classification method developed by several researchers (e.g., Bednarz \& Janvier, 1993; 1996; Bednarz et al., 1992; Filloy \& Sutherland, 1996; Sebrechts et al., 1996; Van Dooren et al., 2002; 2003). The classification scheme consists of three strategy categories (two arithmetic and one algebraic). Table 3 presents two word problems that the participants were asked to solve along with examples of ideal solutions for each strategy type.

A strategy was identified as an algebraic strategy if it contained at least one equation that represented relationships between the known and unknown values contained in the word problem. Additionally, the solution strategy must establish that the problem solver was performing operations on the unknown value(s) (Filloy \& Sutherland, 1996; Kieran, 1992; Van Dooren et al., 2002; 2003). The second category, called manipulating-the-structure, contained arithmetic strategies in which the problem solver altered the problem in a way that makes it solvable without the use of an algebraic equation (Filloy \& Sutherland, 1996; Van Dooren et al., 2002; 2003). The third type of strategy was named according to how it was used. When applied to arithmetic word problems it was called generating numbers. For this strategy the problem solver operates on the known value by using a succession of arithmetic operations in order to "generate" or find the unknown value(s) (Van Dooren et al. 2002; 2003). For algebra word problems the strategy was called guess-and-check. When solving algebra word problems using a 
Table 3

Example Solution Strategies to an Arithmetic and Algebra Word Problem

Arithmetic Word Problem Algebra Word Problem

Participants in a timed fishing contest were competing for the largest total catch. The contestants were only allowed to count carp, bass, and catfish. Three times as many carp were caught than catfish. And 16 more bass were caught than carp. If 34 bass were caught out of 58 total fish, how many carp and catfish were caught?
A car dealership sold 16 cars in one month. There were 2 times as many vans sold than sedans and 4 less sedans sold than trucks. How many vans, sedans, and trucks each were sold?

\section{"Algebraic"}

Let $\mathrm{x}=$ the number of catfish. Then,

$x+3 x+34=58$

$4 \mathrm{x}=24$

$x=6$

6 catfish and $6 \times 3=18$ carp were caught.
Let $\mathrm{s}=$ the number of sedans sold. Then,

$$
2 \mathrm{~s}+\mathrm{s}+\mathrm{s}+4=16
$$

$4 s+4=16$

$4 s=12$

$\mathrm{s}=3$

3 sedans, $3 \times 2=6$ vans, and $3+4=7$

trucks were sold last month. 
"Manipulating-the-structure"

Suppose the number of bass caught was the same as the number of carp caught. Then the total number of fish caught would equal $58-16=42$, and would consist of 7 parts: 1 part catfish, 3 parts carp, and 3 parts bass. Each part would have $42 \div 7=6$ fish. So the number of catfish is 6 , the number of carp is 18 and the number of bass is $34(18+16)$.
Suppose the number of trucks sold was the same as the number of vans sold. Then the total number of vehicles sold would be $16-4=12$. This total can be divided into 4 parts: 2 parts sedans, 1 part vans and 1 part trucks. Each part would consist of $12 \div 4=3$ vehicles. So the number of sedans sold is 6 , the number of vans sold is 3 and the number of trucks sold is $3+4=7$.

"Generating-numbers / guess-and-check"

34 bass were caught. Then $34-16=18$ carp were caught, and $18 \div 3=6$ catfish were caught.

$\begin{array}{cccc}\text { Sedans } & \text { Vans } & \text { Trucks } & \text { Total } \\ 5 & 10 & 9 & 24 \text { (too high) } \\ 4 & 8 & 8 & 20 \text { (too high) } \\ 3 & 6 & 7 & 16 \text { (correct) }\end{array}$

guess-and-check strategy the problem solver is not afforded a known starting value and therefore must approximate one before generating the other unknown value(s); this process is verified or checked, and then, if necessary, repeated until the problem solver arrives at the correct solution (Filloy \& Sutherland, 1996; Nathan \& Koedinger, 2000; Van Dooren et al., 2002; 2003). 


\section{Dependent Variables}

Problem test score. The total number of correct solutions per problem type (arithmetic or algebra) was used to measure the participants' word problem solving performance. This variable was quantified on a numerical scale for each problem type with a range from 0 to 6.

Problem solution agreement. The total number of algebraic solution strategies applied to each type of word problem (arithmetic and algebra) was used to measure the participants' ability to adjust their strategies to fit the defining characteristics of the word problems. Two scores, one for each problem type, quantified on a numerical scale with a range from 0 to 6 was used to represent the total number of algebraic solution strategies applied to each word problem class.

It should be noted that the definition of this variable seems to ignore two of the arithmetic strategies identified earlier, namely, manipulating-the-structure and generating numbers/guessand-check. However, since the total number of arithmetic strategies plus the total number of algebraic strategies applied to each type of word problem should ideally sum to six, the use of this variable will serve as a legitimate measure of a participant's strategy use (Van Dooren et al., 2003). For example, suppose that for the six arithmetic word problems a participant solved four of the problems using algebraic strategies. Then according to the classification scheme the remaining two solutions will be arithmetic. Since the word problems were classified as arithmetic or algebraic it was not necessary to distinguish between the different types of arithmetic solution strategies. The assumption here is that an "expert" problem solver, one who solved the six arithmetic word problems using arithmetic strategies and the six algebra problems using algebraic strategies, would receive 0 for the arithmetic word problems and 6 for the algebra word problems. 
Evaluation score. Participants were asked to rate fictitious student solution strategies from several word problems on a scale from 1 to 10,10 being the maximum. Scores from each strategy type (algebraic, manipulating-the-structure, and generating numbers/guess-and-check) were used to determine evaluation patterns between various subgroups of participants.

Justification of highest score. For each problem, the participants were asked to provide a brief written justification for their highest scored solution. These responses served to support the statistical results by broadly defining the participants' content-specific attitudes.

Attitudes. The term attitudes as it applies to this study is consistent with the current technical usage and refers to a multidimensional construct that includes expressions of beliefs, expressions of feelings and expressions of intentions (Ruffell, Mason, \& Allen, 1998).

\section{Instruments}

Word problem test. A twelve-item, paper-and-pencil test was used to examine the participants' problem-solving skills and strategy preferences. The test items consisted, in part, of six translated questions that appeared in Van Dooren et al. (2003), and six new problems that were modified from these original questions (see Appendix A). Problems were listed in random order.

Solution questionnaire. A questionnaire containing six word problems from the word problem test was used to analyze participants' evaluations of students' word problem solving strategies. The problems were randomly ordered, and equally divided among the three semantic categories (i.e., unequal sharing, transformation, and relation between quantities) with one arithmetic and algebra word problem selected from each category. Three randomly ordered, correct handwritten solutions, which were generated by the author, followed each problem (see 
Appendix $C$ ). The use of fabricated solutions was to aid in keeping a certain degree of consistency between different solution protocols.

Interview protocol. Interviews were conducted to further clarify the themes contained in the participants' justifications from the solution questionnaire, and focused on establishing participants' attitudes and pedagogical content knowledge toward arithmetic and algebraic problem solving methodologies. The interview questions (see Appendix $C$ ) were modified from an earlier study (see Michael, 2002). In particular, questions six and seven were revised to match the context of the current study. Question five was added to determine if the participants understood the word problems. Question eight was added to establish the participants' instructional approaches towards problem solving strategies, and question nine was added to allow the participants opportunities to make additional comments or statements.

\section{Procedures}

After completion of consent forms the word problem test was administered. Participants were given one hour to complete the instrument. No specific instructions were given about how to solve the problems. The use of a standard scientific calculator was permitted and made available to participants upon request.

Following the completion of the word problem test, each participant received the solution questionnaire, and was asked to rate each solution. Participants were told that the solutions were recently gathered by a group of "real" students, and that their scores should reflect their own appreciation for the particular strategies used to solve the word problems. Participants were also asked to justify, in written form, the highest assigned score for each question. Unlimited time 
was allowed for complete of the questionnaire. Within one month of the completion of the test instruments, three participants from each teaching level were interviewed.

Data Collection, Scoring, and Analysis

Solutions to the word problem test were scored as "Correct" or "Incorrect" and then identified according the solution classification scheme (see, Independent Variables). Any question that did not contain a solution was identified as "No Solution". All responses from the solution questionnaire including the written justifications were recorded for each participant. Each of the six interviews were audio taped, and additional notes were made to record any relevant interpretations or impressions made during the interviews.

Research question one was examined using a two-way ANOVA with one betweensubject independent variable, namely, teaching level (elementary versus secondary), and one within-subjects independent variable, namely, problem type (arithmetic versus algebra). Two separate tests were run. The first test used problem test score as the dependent variable and the second test used problem solution agreement as the dependent variable. Both tests used the same set of independent variables, the $F$ test statistic, and a significance level of 0.05 . Each test yielded three effects and two corresponding error terms. Figure 5 provides a graphic summary for the analysis of research question one.

Research question two was examined using a three-way ANOVA with one between subjects independent variable, teaching level (elementary versus secondary), and two within-subjects independent variables, problem type (arithmetic versus algebra), and strategy type (algebraic versus manipulating-the-structure versus generating numbers/guess-and-check). Evaluation score was the dependent variable. Similar to research question one, the analysis for research 
Independent Variables

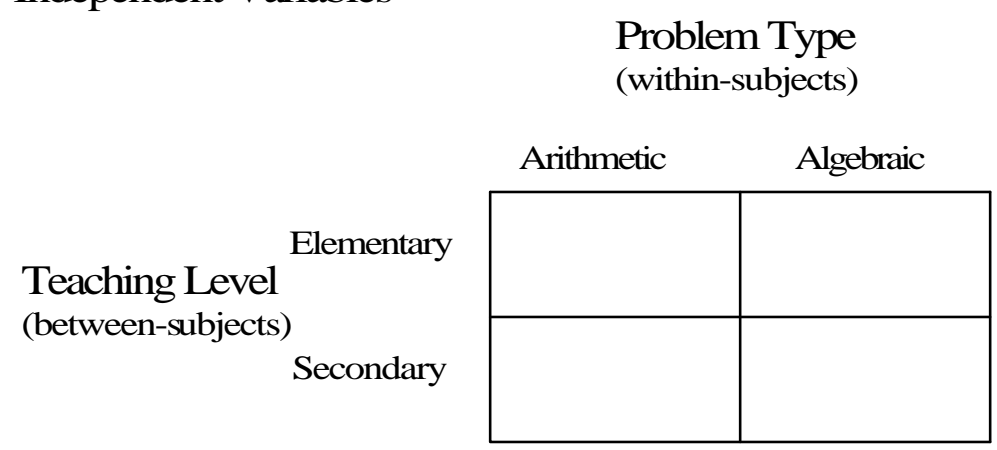

Dependent Variables

\begin{tabular}{l|c|c} 
& Range & Statistic \\
\hline Problem Test Score & $0-6$ & F \\
\hline Problem Solution Agreement & $0-6$ & F
\end{tabular}

Figure 5. Graphic organizer for the analysis of research question one.

question two employed the $F$ test statistic and a significance level of 0.05 . The ANOVA yielded seven effects and four corresponding error terms. Figure 6 provides a graphic summary for the analysis of research question two.

To answer research question three standard Pearson correlations were calculated between the total number of times a participant used a particular strategy on the word problem test and their average evaluation score for that strategy taken from the solution questionnaire. Three correlations were calculated for each type of word problem. To interpret the strength of the correlations each correlation coefficient was compared with its corresponding $p$-value.

Finally, to answer question four the interviews were transcribed and edited. Pseudonyms were used in the construction of the transcripts with additional comments placed within the 


\section{Independent Variables}

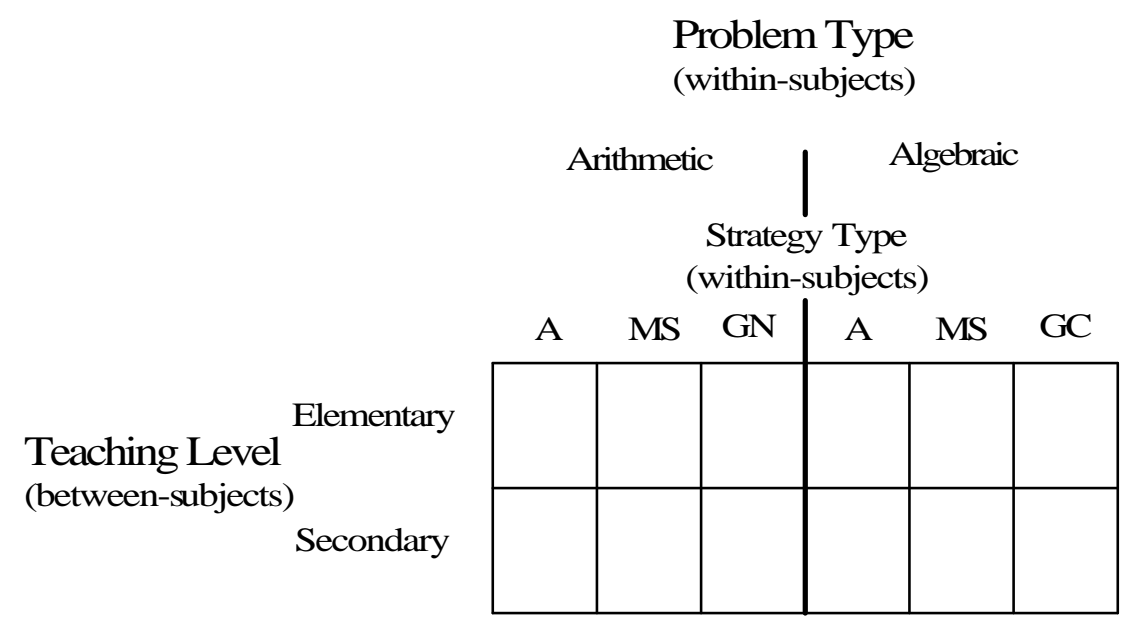

\section{Dependent Variable}

\begin{tabular}{l|c|c} 
& Range & Statistic \\
\hline Evaluation Score & $1-10$ & F
\end{tabular}

Figure 6. Graphic organizer for the analysis of research question two.

Note. Strategies were abbreviated: Algebraic (A); Manipulating the Structure (MS); Generating Numbers (GN);

Guess-and-Check (GC).

transcripts between brackets. A matrix was used to categorize the participants' interview

responses and justifications from the solution questionnaire. The matrix was subdivided by teaching level to aid in the identification of common themes. 


\section{Chapter 4}

\section{Results}

\section{Preservice Teachers' Performance}

One goal of this investigation, as stated in research question one, was to determine which independent variables, if any, had an effect on teachers' word problem solving performance. In order to analyze the performance patterns from the word problem test a two-way ANOVA was used with problem test score (i.e., the number of correct responses) as the dependent variable. The results from this ANOVA are summarized in Table 4.

Table 4

Analysis of Variance for Problem Test Score

$\begin{array}{lllll}\text { Source } & d f & S S & M S & F\end{array}$

Between-subjects

$\begin{array}{lcccc}\text { Teaching Level (TL) } & 1 & 2.45 & 2.45 & 6.44^{*} \\ \text { Error: Subjects (Groups) } & 18 & 6.85 & 0.38\end{array}$

Within-subjects

$\begin{array}{lcccr}\text { Problem Type (PT) } & 1 & 0.90 & 0.90 & 2.00 \\ \text { PT } \times \text { TL } & 1 & 0.00 & 0.00 & 0.00 \\ \text { Error: PT } \times \text { Subjects (Group) } & 18 & 8.10 & 0.45\end{array}$
$p<0.05$.

The results revealed only one significant effect for the between-subjects variable teaching level, which indicated a difference in performance between the elementary and secondary teachers. Secondary teachers were more successful at answering the word problems than their 
elementary counterparts. While elementary teachers correctly answered on average 10.10 of the 12 questions, secondary teachers averaged 11.50 correct responses. The within-subjects variable, problem type, did not influence the teachers' performance as a whole. For the arithmetic problems the teachers answered an average of 5.55 questions correct and 5.25 questions correct for the algebra word problems. This difference was not significant. In addition, the interaction effect between problem type and teaching level was not significant indicating that the elementary and secondary teachers performed similarly over both types of word problems. For the arithmetic word problems the average number of correct responses for the elementary and secondary teachers were 5.20 and 5.90, respectively; and for the algebra word problems these values were 4.90 and 5.60, respectively.

\section{Preservice Teachers' Preferred Strategies}

A second goal articulated in research question one addressed the teachers' algebraic strategy usage. To examine the teachers' strategy usage a second two-way ANOVA was performed with problem solution agreement (i.e., the number of algebraic strategies applied to each problem type) as the dependent variable. The ANOVA is summarized in Table 5. All three effects, teaching level, problem type, and their interaction, were found to be significant.

There was a significant difference in strategy usage between the two groups of teachers. For the 12 word problems the elementary teachers used an average of 6.30 algebraic strategies. The secondary teachers on the other hand used an average of 10.20 algebraic strategies, which revealed their strong preference for algebraic methods. 
Table 5

Analysis of Variance for Problem Solution Agreement

\begin{tabular}{lcccc}
\hline \multicolumn{1}{c}{ Source } & $d f$ & $S S$ & $M S$ & $F$ \\
& Between-subjects & & \\
& & & \\
Teaching Level (TL) & 1 & 18.05 & 18.05 & $9.78^{* *}$ \\
Error: Subjects (Groups) & 18 & 33.25 & 1.85 & \\
& Within-subjects & & \\
& 1 & 32.40 & 32.40 & $46.66^{* *}$ \\
Problem Type (PT) & 1 & 8.10 & 8.10 & $11.66^{* *}$ \\
PT $\times$ TL & 18 & 8.10 & 0.45 & \\
Error: PT $\times$ Subjects (Group) & & &
\end{tabular}

The significant effect for the problem type supported the problem classification scheme that was used in this study. The algebra word problems elicited more algebraic strategies (5 out of 6) than the arithmetic word problems (3.25 out of 6).

The interaction effect between problem type and teaching level indicated that the strategy usages between the two groups of teachers differed significantly. Tukey multiple comparisons were used to analyze the effect of this interaction. This multiple comparisons test indicated a significant difference ( $\alpha=0.05$ ) between the mean number of algebraic strategies used by the elementary teachers and those used by the secondary teachers for both types of word problems. Table 6 provides a summary of the algebraic strategies used by each group of teachers. The secondary teachers showed a strong preference for algebraic strategies for both types of word 
problems. The elementary teachers, however, only applied an average of 1.80 algebraic strategies when answering the arithmetic word problems. For the arithmetic word problems the elementary teachers mainly used arithmetic strategies, and similarly when solving the algebra word problems, they tended to use algebraic strategies. These outcomes suggested that the elementary teachers were more adaptive when choosing solution strategies than the secondary teachers.

Table 6

Average Number of Algebraic Strategies Applied to the Word Problem Test

Arithmetic Problems

Elementary Teachers

Secondary Teachers
1.80

4.70
Algebra Problems

4.50

5.50

Note. Averages are out of a maximum of 6

To further examine the teachers' strategy preferences percentages were calculated for each strategy type used on the word problem test. These percentages are summarized in Table 7. When solving the arithmetic problems $70 \%$ of the elementary teachers' responses were the arithmetic strategy, generating numbers/guess-and-check. Secondary teachers on the other hand only used this strategy on $22 \%$ of the responses from the arithmetic problems. For the algebra word problems both groups of teachers used mainly algebraic strategies. The elementary teachers used slightly fewer algebraic strategies, $75 \%$, compared to the secondary teachers, $92 \%$.

Five out of the ten elementary teachers used arithmetic strategies when solving the algebra word problems. These strategies accounted for $22 \%$ of the total strategies taken from 
this group of problems. Considering their performance, these five teachers each made at least one error when solving the algebra word problems. Even though the elementary teachers as a group answered 4.90 of the 6 algebra problems correctly, this result suggested that half of the elementary teachers experienced some minor difficulty when attempting to solve the algebra word problems. It should be noted that these difficulties did not result in significant differences in performance as evidenced by the non-significant Problem Type $\times$ Teaching Level effect (see Table 4).

Table 7

Preservice Teachers' Percentage use of Strategies on the Word Problem Test

Arithmetic Problems GN/GC 70

22 MS

0

0

A

NS

30

0

78

0
Algebra Problems

GN/GC MS

A

NS

22

$0 \quad 75$

3

Secondary Teachers

6

$0 \quad 92$

2

Note. Strategies are abbreviated: algebraic (A); manipulating-the-structure (MS); generating numbers / guess-andcheck (GN/GC); "no solution” (NS).

The secondary teachers were more successful solving the word problems than their elementary counterparts as stated earlier. Only one out of the ten secondary teachers used an arithmetic strategy when solving the algebra word problems. This particular teacher incorrectly answered one of the problems when attempting to apply an arithmetic strategy. The remaining incorrect responses for this group of problems came from two additional secondary teachers, who each made a single error when attempting to apply an algebraic strategy. None of the 
teachers used the arithmetic strategy manipulating-the-structure when solving the word problems.

Preservice Teachers' Evaluations of Students' Solutions

Research question two addressed the teachers' evaluations of students' solution strategies. Recall, the solution questionnaire presented teachers with three correct solution strategies to each of six word problems. Teachers were asked to rate each solution on a scale from 1 to 10. Teachers' evaluations from the questionnaire were examined using a three-way ANOVA with Evaluation Score as the dependent variable. The results of this ANOVA are presented in Table 8.

The within-subjects effects, problem type and strategy type, and their interaction, Problem Type $\times$ Strategy Type, were found to be significant. As a group the teachers' average ratings for the arithmetic and algebra word problems were 21.68 (out of 30) and 20, respectively. However, more important, the teachers average ratings for each type of strategy were 6.88 (out of 10) for the generating numbers/guess-and-check strategy, 4.90 for the manipulating-thestructure strategy, and 9.07 for the algebra strategy. The high evaluation score for the algebra strategy indicated that the teachers appreciated this class of strategy more than the others. And the low score for the manipulating-the-structure strategy was consistent with the fact that the teachers did not use this strategy at all when solving problems from the word problem test.

To get a better understanding of the interaction effect between Problem Type and Strategy Type, the average evaluation scores for each strategy are presented in Figure 7. 
Table 8

Analysis of Variance for Evaluation Score

\begin{tabular}{|c|c|c|c|c|}
\hline Source & $d f$ & $S S$ & $M S$ & $F$ \\
\hline \multicolumn{5}{|c|}{ Between-subjects } \\
\hline Teaching Level (TL) & 1 & 34.24 & 34.24 & $5.52^{*}$ \\
\hline Error: Subjects (Groups) & 18 & 111.57 & 6.20 & \\
\hline \multicolumn{5}{|c|}{ Within-subjects } \\
\hline Problem Type (PT) & 1 & 85.01 & 85.01 & $10.24^{* *}$ \\
\hline $\mathrm{PT} \times \mathrm{TL}$ & 1 & 0.68 & 0.68 & 0.08 \\
\hline Error: PT $\times$ Subjects (Group) & 18 & 149.48 & 8.31 & \\
\hline Strategy Type (ST) & 2 & 3127.82 & 1563.91 & $54.15^{* *}$ \\
\hline $\mathrm{ST} \times \mathrm{TL}$ & 2 & 189.12 & 94.56 & $3.27^{*}$ \\
\hline Error: ST × Subjects (Group) & 36 & 1039.73 & 28.88 & \\
\hline $\mathrm{PT} \times \mathrm{ST}$ & 2 & 775.42 & 387.71 & $46.33^{* *}$ \\
\hline $\mathrm{PT} \times \mathrm{ST} \times \mathrm{TL}$ & 2 & 6.65 & 3.33 & 0.397 \\
\hline Error: PT $\times$ ST $\times$ Subjects (Group) & 36 & 301.27 & 8.37 & \\
\hline
\end{tabular}

Tukey multiple comparisons revealed several significant differences. Specifically, the average evaluation score for the generating numbers/guess-and-check strategy was higher for the arithmetic problems than for the algebra problems. Furthermore, differences between the average evaluation scores for the arithmetic strategy generating numbers/guess-and-check and 


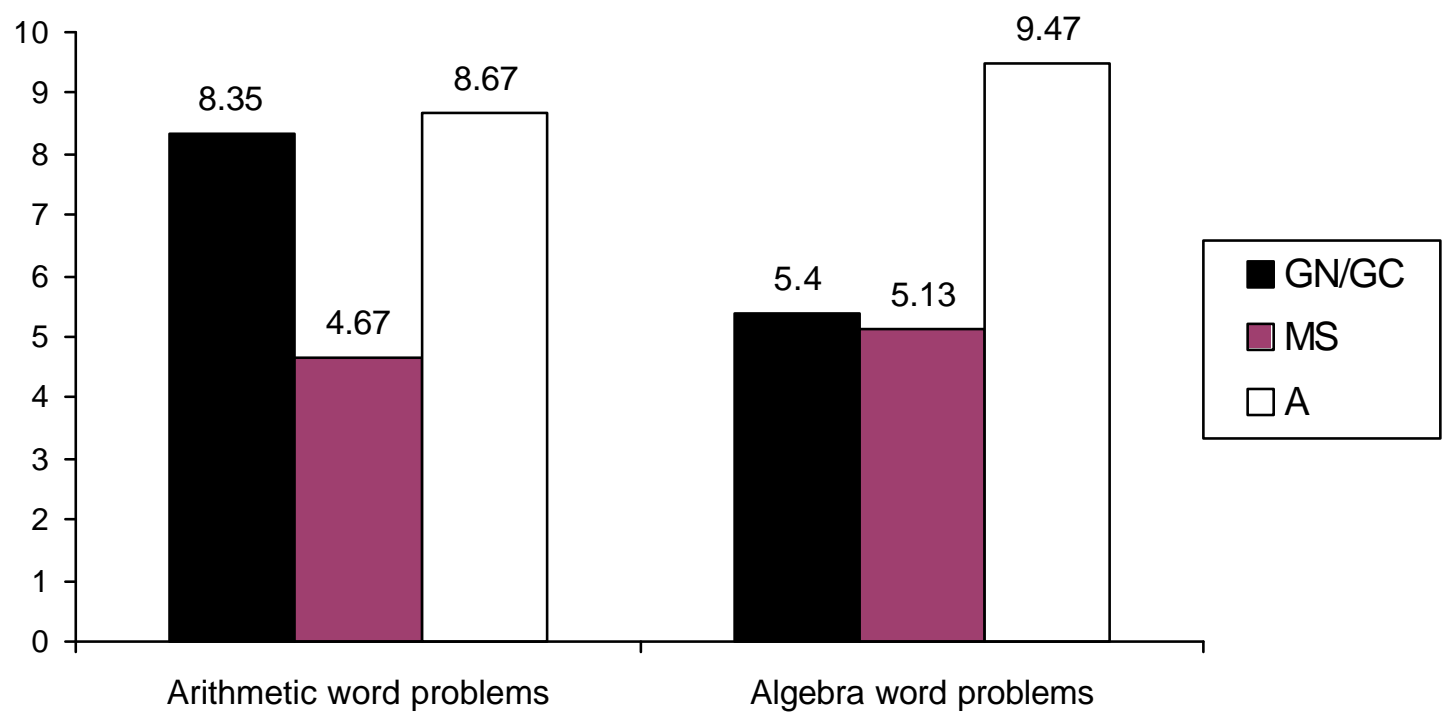

Figure 7. Average evaluation scores (out of 10) for each strategy grouped by problem type.

Note. Strategies are abbreviated: algebraic (A); manipulating-the-structure (MS); generating numbers / guess-and$\operatorname{check}(\mathrm{GN} / \mathrm{GC})$.

the algebra strategy were found to be significant for the algebra word problems only. Thus, the teachers showed greater variety in their evaluations of solutions to the arithmetic problems. For the algebra word problems they overwhelmingly favored algebraic solutions.

The ANOVA results also showed a significant between-subjects effect for teaching level and the interaction Teaching Level $\times$ Strategy Type. Of these two, the interaction effect was most important because it indicated that teaching level modified the main effect for strategy type. Figure 8 presents the average evaluation scores assigned by the elementary and secondary teachers for each of the three strategies. 


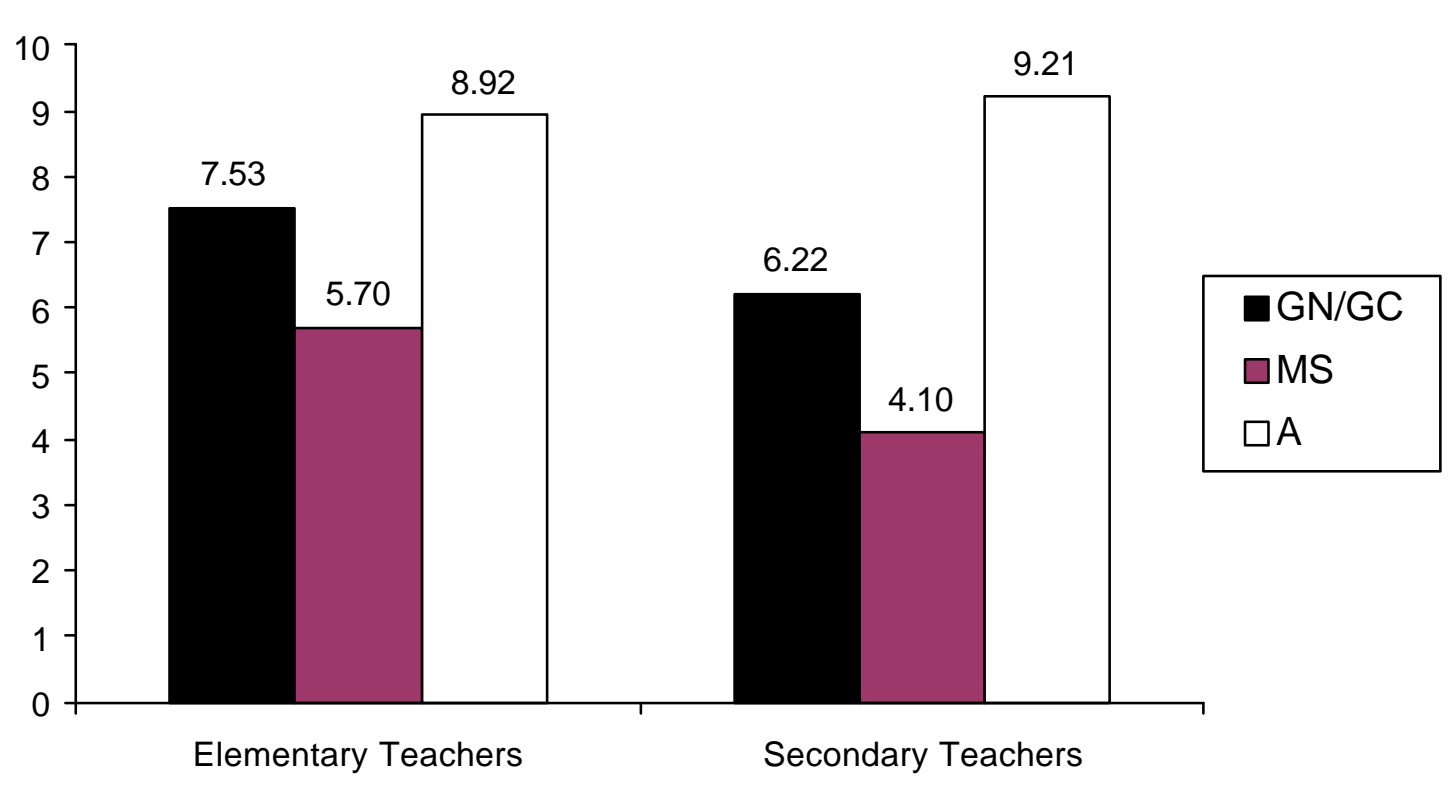

Figure 8. Average evaluation scores (out of 10) for each strategy grouped by teaching level. Note. Strategies are abbreviated: Algebraic (A); Manipulating-the-Structure (MS); Generating Numbers (GN); Guess-and-Check (GC).

The elementary teachers' average evaluation scores for the arithmetic strategies seemed to be higher than the secondary teachers' scores (7.53 versus 6.22 for generating numbers/guessand-check and 5.70 versus 4.10 for manipulating-the-structure, respectively). And similarly, the elementary teachers' average evaluation score for the algebraic strategy appeared to be lower than that of the secondary teachers (8.92 versus 9.21, respectively). However, Turkey multiple comparisons revealed no significant differences between these three pairs of values. Thus, the teachers did not demonstrate a greater appreciation for those strategies that were associated with their specific program of study. 
Another important interpretation regarding teachers' evaluations comes from the threeway interaction, Problem Type $\times$ Strategy Type $\times$ Teaching Level. This effect showed that teaching level did not modify the significant two-way interaction between problem type and strategy type. Thus, differences between the elementary teachers' evaluation scores and the secondary teachers' evaluation scores to strategies to the arithmetic and algebra word problems were not statistically significant at the 0.05 level.

\section{Relation Between Problem Solving Behavior and Didactic Behavior}

The purpose of research question three was to determine whether the teachers' evaluations of students' strategies were influenced by their own strategy preferences.

Correlations were found between the number of times each teacher used a particular strategy and his or her own average evaluation for that particular strategy. The correlations were divided over the two classes of word problems, and are presented in Table 9.

Table 9

Correlations Between Frequency of Strategies Used and Average Evaluation Scores

Type of Problem

Type of Strategy

Generating number / guess-and-check

Algebra
Arithmetic

$0.52^{\dagger \dagger}$

0.27
Algebra

$0.38^{\dagger}$

$-0.02$

Note. The strategy "manipulating-the-structure" was omitted since preservice teachers did not use this strategy. ${ }^{\dagger} p<0.05$, one-tailed. ${ }^{\dagger \dagger} p<0.01$, one-tailed. 
Only the correlations from the arithmetic strategy generating numbers/guess-and-check were significant. Correlations could not be found for the second arithmetic strategy, manipulating-the-structure, because the teachers did not use this strategy when solving the word problems. However, considering the fact that the manipulating-the-structure strategy was the lowest rated strategy, the teachers' ratings for this particular strategy were consistent with their strategy usage. For the algebraic strategy the teachers' evaluations may have been based on criteria that went beyond their own problem solving behaviors. Several of the elementary teachers for example used two or fewer algebraic strategies when solving the arithmetic word problems, however, their evaluations for this particular strategy were as high as some secondary teachers who used four or more algebraic strategies from the same set of word problems.

\section{Preservice Teachers' Justifications}

While completing the solution questionnaire the teachers were asked to provide a brief justification for their highest score from each problem. These justifications provided a way to define the teachers' attitudes with respect to arithmetic and algebraic problem solving methodologies. Although there were many similarities between the justifications of the elementary and secondary teachers, I will first discuss the elementary teachers justifications followed by a similar discussion for the secondary teachers.

Preservice elementary teachers' justifications. When evaluating students' solutions to the arithmetic problems elementary teachers gave high scores to both the arithmetical method generating number/guess-and-check and the algebraic method (see Figure 9). Their average ratings for these two strategies were 9.07 and 8.43, respectively. For the arithmetic strategy 
Elementary Teachers

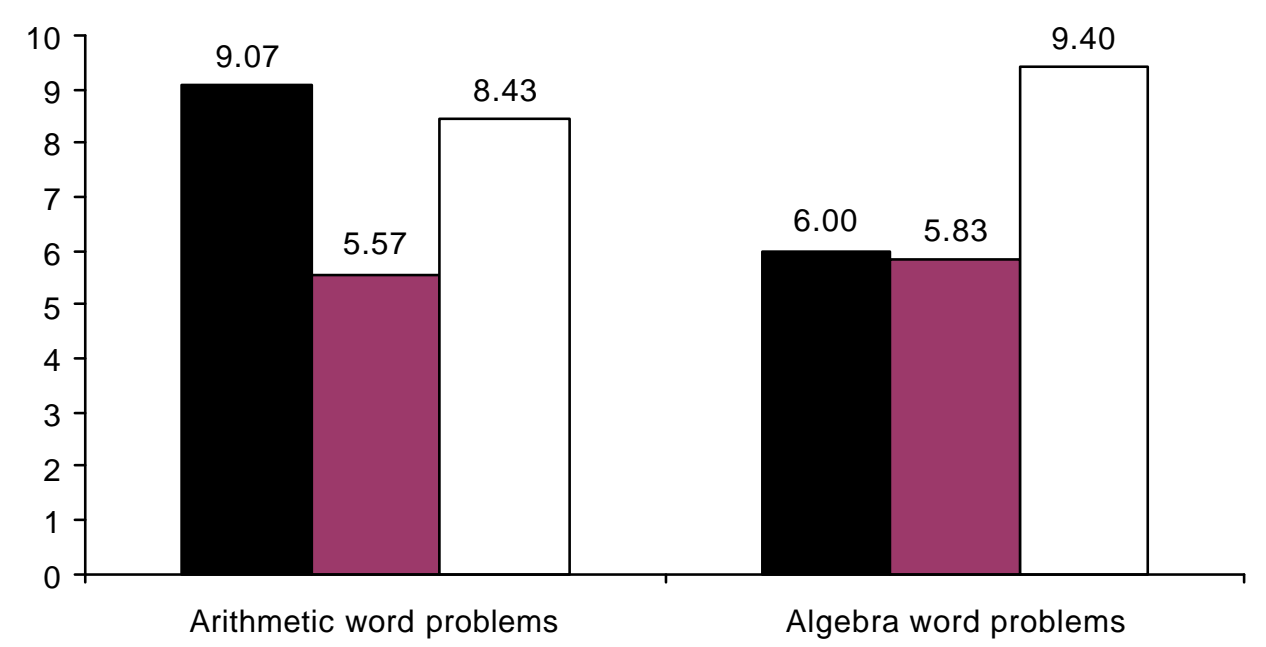

Secondary Teachers

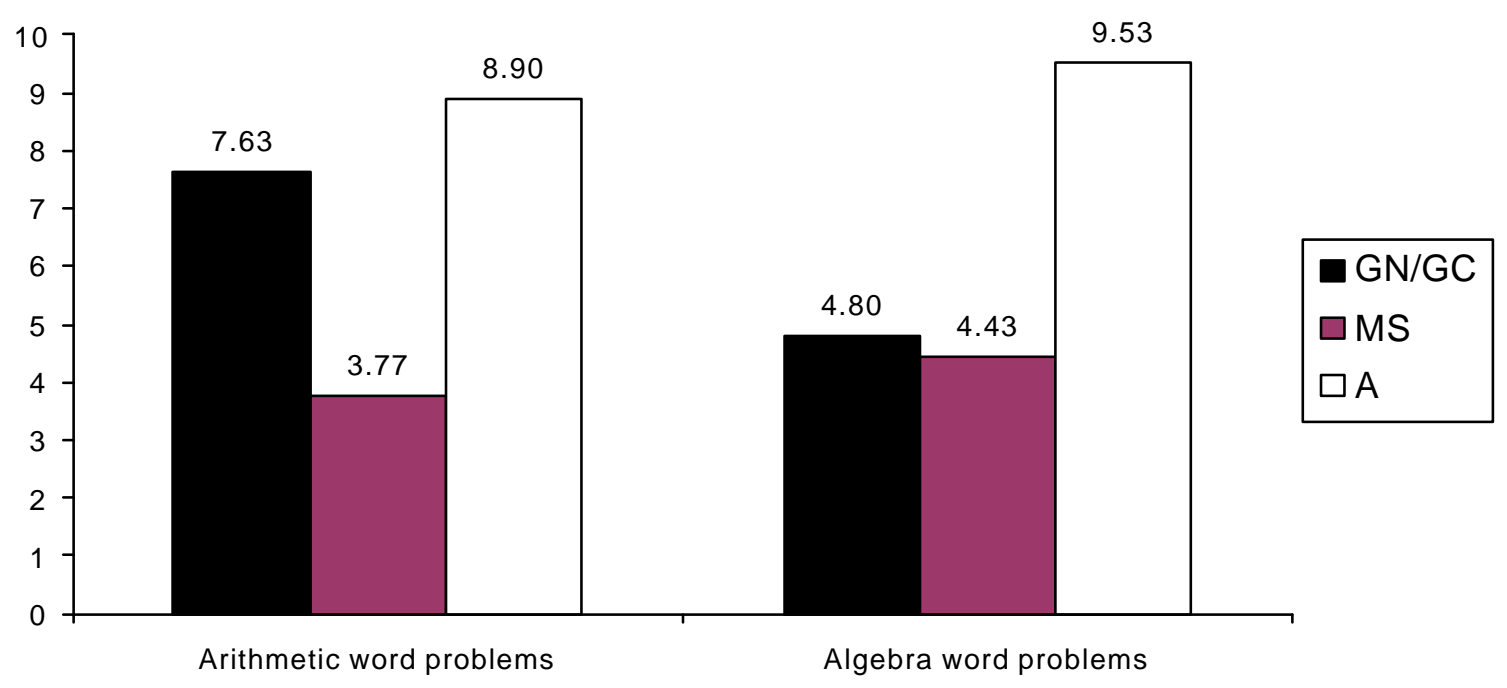

Figure 9. Average evaluation scores given to students' strategies separated by teaching level.

Note. Strategies are abbreviated: algebraic (A); manipulating-the-structure (MS); generating numbers / gues s-andcheck (GN/GC). 
generating number/guess-and-check the elementary teachers' justifications reflected their preferences for direct and economical strategies:

"Basic and simple. No need for extra work. Correct and to the point."

"Work was kept simple and with as few operations as possible."

"Solution was easy to read and to the point."

"They stated their answer logically using the least amount of steps."

Several of the elementary teachers' justifications for this strategy also indicated that they considered the simplistic nature of the arithmetic problems when determining their ratings:

“For this problem I thought it wasn't necessary to use an algebraic equation, because simple math can be calculated"

"Work was well spaced and used no unnecessary variables."

"The easiest possible approach. No need to make the problem harder than it really is."

As stated, for the arithmetic problems elementary teachers often gave the algebraic strategy their highest rating even though many of them did not use algebraic strategies when solving problems from the word problem test. In these cases the elementary teachers' did not comment on how well the solution "matched" the word problem. Instead, they seemed to be motivated by solution characteristics that were easy to follow and demonstrated students' ability to construct and organize a logical argument. In their minds the algebraic strategy represented the best choice as was illustrated by the following explanations:

"Good use of algebra. Shows logical reasoning to derive the correct answer."

"All work was shown and was logical. Long enough to check."

"Information is well organized and work shown is thorough."

"This is the most logical way to go about getting the answer." 
For the algebra problems the elementary teachers gave the highest score to the algebraic strategy. The majority of the justifications for this strategy did not refer to the specific characteristic of the word problem itself. Instead, the elementary teachers preferred the algebraic solution because it was easy to follow, well organized and logical. The elementary teachers also felt that the algebraic equation represented the best method for organizing problem information. The following examples characterized these attitudes:

\footnotetext{
"Work is easy to follow and perfectly puts the word problem into an algebraic equation"

"The algebraic equation helps to break up the problem into known and unknown parts to help solve the problem."

"The algebra solution was my favorite because the algebraic equation is easy to understand and solve." "I could understand their logic and they set-up the problem beautifully by using an equation."

"The most clearly explained answer. All variables were identified and a proper equation was set-up and solved."
}

Out of the ten elementary teachers two teachers preferred the algebraic strategy because it was the most general solution and, consequently, the one that could be applied to many different types of problems. However, as a whole the elementary teachers did not consider the mathematical relevance of the algebraic strategy from this point of view.

As stated earlier, none of the teachers used the manipulating-the-structure strategy when solving the word problems. Considering this, it is not surprising that the elementary teachers gave the lowest ratings to this particular strategy. Even though they were not asked to justify their lowest score, a few of the elementary teachers felt compelled to comment on this particular strategy. These comments suggest that the manipulating-the-structure strategy was "confusing" and "not well organized." One teacher even said that the strategy "made no sense." 
Preservice secondary teachers' justifications. For the arithmetic word problems the secondary teachers' gave the highest score to the algebraic strategy (see Figure 9). The majority of their justifications cited the algebraic equation as the best method for organizing problem information and constructing a clear, easy to understand solution. Moreover most of the secondary teachers did not make explicit reference to the problem itself; they were only concerned with the characteristics of the solution process. Typical justifications from this set of responses included the following:

\footnotetext{
"Good equation; easy to follow; rational."

"Had an equation. The solution is easy to read and follow. The variable x was well defined."

"The algebraic solution clearly defined a variable and an equation with valid reasoning."

"Student defined a variable then set-up all of the unknowns in terms of the variable. I can see exactly what the student has done and I do not have to guess at his or her understanding."
}

When evaluating solutions to the algebra word problems, again, the secondary teachers gave highest scores to algebraic strategies (see Figure 8). Their justifications for the algebra word problems were more varied than their justifications for the arithmetic problems, and generally could be characterized by two sets of responses. The first set of justifications was much like the justifications to the arithmetic problems; that is, secondary teachers favored the algebraic strategy because it contained an equation that provided a clear and organized solution process. The second set of justifications described the algebraic method as the correct method for solving word problems and one that could be generalized to a variety of problems:

\footnotetext{
"Demonstrated a thorough understanding of the correct format used to solve a word problem"

"This was the most algebraic method and is a method that will work with more difficult problems."

"More algebraic and a more universal method."
} 
Out of the 30 justifications for the algebra problems only two referred to the way the teacher solved the problem. For instance, one secondary teacher mentioned that she chose the algebra solution because it was the same method that she used when solving similar word problems.

As evidenced by their justifications, the secondary teachers did not seem to consider how closely the algebra solutions matched the algebra word problems. As stated, they favored the algebraic method because it demonstrated, by way of an equation, that the problem solver could construct a clear, logical and practical solution. Moreover the secondary teachers favored algebraic strategies because they could easily follow the solution from beginning to end. Similar to the elementary teachers, the secondary teachers also gave the lowest score to the manipulating-the-structure strategy for both types of word problems. And much like the elementary teachers, several secondary teachers commented on the difficult nature of this particular strategy. In particular, a number of secondary teachers felt the manipulating-thestructure solution was hard to follow and difficult to understand.

\section{Interviews: A Closer Look at Preservice Teachers' Attitudes}

The interviews provided a means to understand the teachers' pedagogical content knowledge towards problem solving in general, and also to further define their attitudes as established by their responses to the solution questionnaire. The three elementary teachers who were interviewed, Holly, Jay, and Stacie, were each specializing in mathematics, and each of the secondary teachers, Beth, Mike, and Raymond, were mathematics majors.

The nine questions contained in the interview protocol were incorporated into three subsections. The first subsection will examine how the teachers viewed their own problem solving abilities. The second subsection will look at how the teachers would access and identify 
"effective" problem solving strategies and how they might teach problem solving to a hypothetical classroom of students. And the third subsection will focus on the teachers motivations for their lowest and highest rated solutions from the solution questionnaire.

Preservice teachers' descriptions of their own problem solving abilities. Most of the teachers (4 out of 6 ) viewed themselves as efficient problem solvers. The three secondary teachers each commented on their preference for using equations. Only one secondary teacher, Beth, reported that she had a weakness solving "elementary" (arithmetical) type problems. The elementary teachers were less certain when assessing their problem solving abilities. For example, Stacie said that she always began a solution by using a trial-and-error process, and if this process failed, she would then try to set-up an equation. Another elementary teacher, Holly, described her problem solving skills as "decent." She further added that she finds constructing an equation to be a difficult task. Overall, the secondary teachers seemed more confident in their problem solving abilities than the elementary teachers. This result may help explain why the secondary teachers outperformed the elementary teachers on the word problem test.

The second question asked teachers to describe the kinds of things that usually trigger their actions in problem solving situations. Table 10 contains the number of algebraic strategies used by each teacher on the word problem test. These values will be used to help validate the teachers' responses to this particular question.

The majority of the teachers' responses described a similar process: begin with a minor strategy, for example, restating the problem information or constructing a diagram, and then use the information in its reduced form to construct an equation. In all these cases, with the 
exception of one elementary teacher, Holly, the teachers were not concerned with the specific characteristics of the problem. Holly, by contrast, said that if a problem was simple enough Table 10

The Number of Algebraic Strategies Used on the Word Problem Test by the Interviewees

Type of Problem

\begin{tabular}{ccc} 
Elementary Teachers & Arithmetic & Algebra \\
\hline Holly & 1 & 4 \\
Jay & 3 & 6 \\
Stacie & 0 & 1 \\
Secondary Teachers & 5 & \\
Beth & 5 & 6 \\
Mike & 4 & 6 \\
Raymond & 4 & 6 \\
\hline
\end{tabular}

she would use arithmetic to find a solution, but if the problem seemed more complicated she would try to construct an algebraic equation. Holly's response was consistent with her strategy usage (see Table 10). For the arithmetic problems Holly mainly used arithmetic strategies and, similarly, for the algebra problems her preference was for algebraic strategies. For Jay, Beth Mike, and Raymond their responses were also consistent with their use of strategies; they explicitly mentioned that in the process of solving a problem they would construct an algebraic equation, and their strategy usage reflected this process. Stacie also mentioned her preference 
for equations, but as evidenced by her strategy usage, she preferred arithmetic strategies when solving the word problems. Recall that when asked to describe her problem solving abilities Stacie said that she liked to begin a problem using a trial and error process. When solving the algebra problems Stacie in fact did use the strategy generating numbers/guess-and-check successfully on five occasions. Thus, in light of question one Stacie's use of strategies was consistent with her response.

\section{Preservice teachers' conceptions of effective strategies and their approaches to the}

teaching of problem solving. When asked to describe the characteristics of an effective problem solving strategy, the teachers seemed to focus on the problem solving process itself rather than on a specific type of strategy. Moreover, they all felt that an effective strategy contained a clear or logical set of steps that could be easily followed from beginning to end. The teachers were also asked how they would discriminate between "good" and "bad" problem solvers when examining the work of their students. Again, the teachers felt that a "good" strategy was one that was easy to follow and clearly described a student's thinking from beginning to end. The responses to both of these questions showed that the teachers were more concerned with the clarity of the solution process rather than the mathematical relevance of the process itself. This outcome was also noted when examining the teachers' justifications. The responses to these questions also helped to better understand why so many teachers gave low ratings to the manipulating-the-structure strategy. As discussed in a previous section, several teachers commented on the confusing and hard to follow nature of this strategy in their justifications. Even though the manipulating-the-structure strategy at times presented a clever and 
nontraditional approach to a solution, the teachers criticized the process because it was hard to follow and, more important, because it did not provide a clear description of students' thinking. The final question in this subsection asked teachers to comment on how they would approach the teaching of problem solving in their own classroom. The teachers' responses to this particular question reflected their own teaching level. This was especially evident with the secondary teachers who each mentioned the steps that make-up an algebraic strategy such as "defining a variable" or "constructing equations." However, the elementary teachers responses seemed to show a broader approach to teaching problem solving. For example Holly's response indicated a pluralistic approach to teaching problem solving which was determined by a student's learning style:

"Not everyone learns the same. So you would obviously want to show that problems could be solved in more than one way."

Another elementary teacher, Jay, commented on the flaws of identifying certain types of problems with certain types of strategies:

"I would not so much teach 'this is how' to do a problem, but 'this is why' you solve the problem this way.

"If you teach students how to solve a certain type of problem, they will do fine as long as they're solving that kind of problem."

It is also curious to note that during the interviews the secondary teachers responded to this question in a quick and almost automatic way. The elementary teachers on the other hand seemed to be more thoughtful and careful when articulating their response to this question.

Preservice teachers' explanations of the lowest and highest rated solutions. Before the teachers were asked to comment on their specific ratings, they were shown the questionnaire and asked if they had any trouble understanding the questions. All of the teachers said that they 
understood the problems. In some cases teachers said that they had to read certain problems more than a few times in order to decipher the question. Only one elementary teacher, Stacie, commented on the solutions. She added that the manipulating-the-structure solution strategy was at times difficult to understand.

The teachers were asked to further explain their ratings from the solution questionnaire while examining their particular responses. Overall, the interviewees' responses were consistent with the trends that were found in the justifications. In 15 out of the 18 highest ratings the secondary teachers that were interviewed selected the algebraic strategy. The secondary teachers cited that algebra strategy for its well organized and easy to follow format. Only one secondary teacher, Mike, said that he chose the algebraic strategy because it corresponded to the way that he solved the problems himself.

When it came to the lowest rated strategies, Mike assigned low scores to the manipulating-the-structure strategy because he found this particular strategy difficult to follow. The other two secondary teachers, Beth and Raymond, assigned low scores to the generating number/guess-and-check strategy because they felt that an approach based on trial-and-error was inefficient and demonstrated a lack of understanding on the part of the student. Raymond's comment typified this attitude:

“In some cases they used 'guess-and-check' and they got the correct answer. But they don't know why or how the answer could be found by using a more algebraic technique."

For Raymond a mathematical understanding of the problem is evidenced by the use of algebra.

The elementary teachers' highest rated strategies showed that they matched the strategy to the type of word problem more often than the secondary teachers. For the 18 highest rated 
strategies the elementary teachers chose the algebraic strategy 11 times. However, for 7 of the 9 highest rated strategies from the arithmetic word problems the elementary teachers chose the arithmetic strategy generating numbers/guess-and-check. The elementary teachers preferred this strategy for arithmetic problems, because it was simple and to the point. Two of the elementary teachers, Holly and Stacie, thought that using algebra to solve a simple word problem requires a lot of unnecessary work. The statements made by Holly and Stacie here were similar to the justification made by several elementary teachers.

When evaluating strategies from the algebra word problems all three elementary teachers rated the algebraic strategy the highest. Again, similar to the secondary teachers, the elementary teachers preferred the algebraic strategy because it was believed to be logical and easy to understand. Jay's comment about algebraic strategies seemed captured this belief:

"I like algebraic strategies because I believe everything has to be very logical. Algebraic work does that. In my opinion it is mathematically sound."

For 15 of the 18 problems the elementary teachers gave the manipulating-the-structure strategy the lowest score. Both Holly and Stacie said that they could not follow the arguments presented by this strategy, and Jay disliked the manipulating-the-structure strategy because he felt the logic was "strange." The reactions of the elementary teachers to the manipulating-thestructure strategy were consistent with the previous statements made by several teachers in their justifications.

\section{Summary}

Performance and strategy usage. A significant difference in performance was found for the independent variable teaching level only (see Table 4). The secondary teachers were more 
successful solving the word problems and were found to be more confident in their problem solving abilities than the elementary teachers. The type of word problem did not affect the teachers' performance. The teachers performed similarly over both the arithmetic and the algebra word problems, and no single group of teacher (elementary or secondary) was found to outperform the other on either of the two classes of word problems.

The variables, teaching level and problem type, and their interaction were each found to yield a significant difference on the number of algebraic strategies used by the teachers (see Table 5). The significant problem type variable supported the problem classification scheme used in the study and developed by Bednarz and Janvier (1993; 1996). Specifically, it was found that those problems classified as "algebra" word problems induced more algebraic strategies than those problems classified as "arithmetic" word problems. The secondary teachers were found to use more algebraic strategies than the elementary teachers, and they demonstrated a strong preference for algebraic strategies when solving both the arithmetic and the algebra word problems. By contrast, the elementary teachers' problem solving behaviors were more adaptive when compared to the secondary teachers. The elementary teachers often chose strategies that matched the classification of the word problems, i.e., when solving the arithmetic problems they preferred arithmetic strategies and when solving the algebra problems they preferred algebraic strategies.

Evaluation of students' solution strategies. All three independent variables, teaching level, problem type and strategy type were found to yield significant differences on the teacher's evaluation scores (see Table 8). In addition, the interaction effects, Problem Type $\times$ Strategy Type and Teaching Level $\times$ Strategy Type were each found to be significant. 
The algebra strategy was the highest rated strategy for both the arithmetic and the algebra word problems. The teachers demonstrated more variety in their evaluations to strategies from the arithmetic problems. For the algebra word problems the teachers favored the algebra strategy. The manipulating-the-structure strategy was the lowest scored strategy for both types of problems.

The analysis of evaluation scores by teaching level found that the teachers did not assign higher evaluation scores to those strategies that were commonly associated with their particular program of study. Moreover, differences between elementary and secondary teachers' ratings of the three strategies to the arithmetic and algebra word problems were not found to be significant.

Relation between problem solving behavior and didactic behavior. With the exception of the algebra strategy the teachers' strategy preferences were reflected in the their evaluations of students' solutions. Positive correlations were found over both problem types between the frequency of use for the arithmetic strategy generating number/guess-and-check and the teachers' average evaluations scores for that strategy. The manipulating-the-structure strategy was not used at all by the teachers and, consequently, received the lowest evaluation scores for the three strategies. Correlations for the algebra strategy were not significant (see Table 9). Specifically, several elementary teachers gave high evaluation scores to the algebra strategy even though this method was not their preferred method for solving word problems. This result suggests that many of the elementary teachers did not rely solely on their own problem solving preferences when evaluating algebraic solutions.

Content-specific attitudes. Both groups of teachers showed a preference for algebraic solution strategies. This outcome was most noted for the secondary teachers who favored the 
algebra strategy almost exclusively. Considering the justifications and interview data it was clear that the teachers generally valued the algebra solution, not for its mathematical relevance, but because it provided a clear and logical solution process that allowed them to understand students' thinking. The teachers' attention on the solution process was also noted in the ways they defined and assessed "effective" problem solving strategies in general. Unlike the algebra solution strategy, the manipulating-the-structure strategy received the lowest ratings even though it provided a nontraditional and sometimes clever approach to a solution. The teachers gave low ratings to this strategy because the written descriptions were, at least in their minds, unclear and illogical.

Considering their written justifications, the elementary teachers more often referred to the characteristics of the word problems than the secondary teachers. The interview data supported this outcome by showing that the elementary teachers' pedagogical content knowledge towards problem solving was broader than the secondary teachers. While the secondary teachers' responses reflected their preference for algebraic solution methods, the elementary teachers considered other factors such as students' learning styles and multiple solutions when discussing their instructional approaches towards problem solving. The elementary teachers' pedagogical content knowledge may also help explain why several elementary teachers gave high evaluation scores to the algebra strategy when they themselves rarely used this strategy on the word problem test. In general the teachers did not explicitly state whether their choices of highest rated solutions were motivated by their own preferred method for solving the word problems. 


\section{Chapter 5}

\section{Conclusion}

In terms of performance the secondary teachers correctly solved more word problems than the elementary teachers. However, it was also found that the type of word problem did not influence the teachers' performance. Contrary to the results sited by Van Dooren et al. and Schmidt, the elementary teachers who participated in this study did not experience significant difficulties solving algebra word problems.

Considering the teachers' strategy preferences the results cited here are generally consistent with those findings reported by both Van Dooren et al. and Schmidt. It was found that secondary teachers relied almost exclusively on algebraic strategies for both types of word problems. And while some of the elementary teachers made errors when trying to apply arithmetic strategies to algebra problems, the majority of them demonstrated flexibility in their strategy preferences by choosing those types of strategies that were most appropriate to the given problem situations. Also, contrary to the participants in Van Dooren's study, when solving the word problems the teachers in the current study did not use the manipulating-the-structure strategy.

With respect to the teachers' evaluations of students' solutions, there were three notable differences between the findings presented here and those cited by Van Dooren et al. (2002). First, the teachers did not demonstrate a greater appreciation for strategies that were typical to their teaching level. Second, the teachers surveyed by Van Dooren et al. often "matched" their highest rated strategies to the type of word problem. As evinced by their evaluations, the teachers in the present study generally did not consider the nature of the word problems when 
choosing their highest rated strategies. Finally, Van Dooren et al. found that the elementary teachers they investigated demonstrated more variety in their evaluations when compared with the evaluations of the secondary teachers. Considering the results from the current study, it was not possible to draw such a conclusion. The analysis of the evaluation scores from each type of strategy for each type of problem revealed no significant difference between the elementary teachers and the secondary teachers.

Van Dooren et al. also found that teachers' problem solving preferences influenced their didactic behavior. The findings in the current study did not completely support this outcome. Considering the two arithmetic strategies, the teachers consistently gave higher evaluation scores to those strategies that they themselves applied while solving the word problems. However, this was not the case for the algebra strategy. Several elementary teachers in particular were found to have a greater appreciation for algebraic strategies even though they rarely used these strategies to solve word problems.

With respect to the teachers' justifications, the results cited here were similar to those reported by Van Dooren et al. When compared to the secondary teachers, the elementary teachers more often referred to the type of problem when justifying their highest scored solutions. This outcome was most noted for solutions to the arithmetic problems. For the algebra word problems both groups of teachers often cited the algebra solution for its organization and clarity. A small number of secondary teachers viewed the algebra solution as the "most appropriate" or "most general" method for solving the word problems. The manipulating-the-structure strategy was the least appreciated of the three strategy classes. 
Several teachers disliked this strategy because it was illogical and did not provide a clear description of the solution process.

Finally, the interview data provided additional information regarding teachers' attitudes and pedagogical content knowledge, which provided support to the overall findings. The elementary teachers were found to be less confident in their problem solving abilities than their secondary counterparts. These "self-assessment" differences were reflected in the performance results. The elementary teachers' pedagogical content knowledge was found to be more broad than secondary teachers as evidenced by their attention to learning styles and multiple representations when asked to articulate their approaches to problem solving instruction. The nature of the elementary teachers' pedagogical content knowledge may explain why they often made reference to the type of problem in their justifications. Moreover, it may also help clarify why several of the elementary teachers appreciated algebraic methods even though they rarely used these methods when solving the word problems. Overall the teachers' ideas about problem solving strategies tended to be process oriented. When defining the characteristics of an "effective" problem solving strategy the teachers generally did not seemed concerned with the mathematical relevance of a strategy. Instead, they tended to refer to particular steps within a particular problem solving method. Considering both the interview responses and justifications it was not clear whether the teachers gave high scores to certain solutions because those were the same methods they used while solving the word problems. 
Discussion

\section{Implications of the Study}

Both Van Dooren et al. (2002; 2003) and Schmidt (as cited in Van Dooren et al., 2002; 2003) have questioned the potential of prospective teachers to support future students transitioning from arithmetic to algebra. In particular these studies have revealed problematic features of teachers' content knowledge and attitudes toward arithmetical and algebraic problem solving methodologies. The secondary teachers in these investigations were shown to have a strong preference for algebraic strategies. And because of their inadequate understanding of algebra, many of the elementary teachers in these studies could not efficiently apply algebraic strategies. Moreover, Van Dooren et al. found that teachers showed less appreciation for those classes of strategies that were typically outside the domain of their level of instruction.

The results of the present study do support some of the concerns raised by Van Dooren et al. and Schmidt and extend them to an American context. The secondary teachers who participated in this study held the same stubborn preferences for algebraic strategies as Canadian and Belgian teachers. The present study also extends the work of Van Dooren et al. by more thoroughly defining teachers' attitudes towards problem solving methodologies. Many of the teachers were found to favor algebraic solution strategies, because these solutions were considered "clear," "organized" and "logical." Moreover, the teachers frequently did not consider the mathematical relevance of the strategies in their ratings, and they consistently demonstrated lower appreciation for "non-traditional" problem solving approaches.

The main differences between the results of the current study and those cited by Van Dooren et al. and Schmidt were associated with the elementary teachers. The elementary 
teachers in this study were comfortable using algebraic methodologies and the majority of them demonstrated flexible strategy preferences by often matching their choice of strategy to the defining characteristics of the word problem. They also more frequently made explicit reference to the word problems than did the secondary teachers when justifying their highest rated solutions. The interview data also provided evidence that the elementary teachers possessed a broad pedagogical content knowledge base. Unlike Van Dooren et al. (2002), consistent positive correlations between teachers' problem solving behaviors and their didactic behaviors were not found for all strategy types in this study. For the algebra solution in particular the elementary teachers regularly assigned high scores to this solution even though they rarely used algebraic strategies when solving the word problems. The pedagogical content knowledge of the elementary teachers may have permitted them to look beyond their own problem solving preferences when assigning scores to these solutions.

With regard to the elementary teachers' performance and strategy usage, the findings of this study are quite positive, and consequently I am somewhat confident in the potential of these teachers to support the algebraic development of their future students. The secondary teachers on the other hand were also shown to perform well when solving the word problems, however, the range of their strategy choices was very narrow, and reflected a strong preference for algebraic methodologies. I therefore question whether these secondary teachers will develop the attitudes and pedagogical dispositions that will permit them to support beginning algebra students who enter the classroom with concentrated backgrounds in arithmetic.

My biggest concern, however, comes from the findings regarding the attitudes that both groups of teachers held towards "effective" problem solving strategies and non-traditional 
problem solving approaches. The teachers tended to define an effective strategy in terms of particular steps in a process without taking into account the mathematical relevance or mathematical appropriateness of the strategy itself. They also did not appreciate the manipulating-the-structure strategy for its non-traditional and often clever approach to a solution. Thus, I have some concern that these teachers will not be able to understand and support students' own idiosyncratic problem solving methodologies that differ from the standard algebraic or arithmetical approaches most commonly found in textbooks. And considering some of the current recommendations for mathematics education and instruction (e.g., CBMS, 2001; NCTM, 2000), I question whether these teachers will be able to instill in their students diverse and well integrated problem solving habits that extend beyond mere procedures to be used only for particular problem situations.

\section{Recommendations for Teacher Education}

Considering the findings of this study and the concerns raised regarding the prospective teachers' content knowledge and attitudes toward arithmetic and algebraic problem solving strategies, I would like to make the following recommendations for improving teacher training at the postsecondary level. These suggestions are consistent with some of the current recommendations for elementary mathematics instruction (e.g., Carpenter \& Levi, 2000; Kaput and Blanton, 2001) such as including algebraic reasoning activities throughout the K-6 curriculum. These suggestions are also in accord with recommendations for teacher education (e.g., CBMS, 2001; Ma, 1999) that value the importance of developing a deep and flexible understanding of mathematics. First, reiterating a recommendation made by Van Dooren et al., I too believe that mathematics education should address critical issues regarding students' 
transition from arithmetic to algebra. Particularly, in the case of prospective elementary teachers, who will one day be responsible for initiating the algebraic reasoning of elementary students, I suggest creating an algebra course specifically for this group of teachers that would include practical teaching approaches and critical issues in algebra instruction. Furthermore, to encourage prospective teachers' flexible use of their content knowledge, mathematics educators must find ways to help prospective teachers become more aware of their own mathematics habits and perspectives. For example, the testing instruments used in this study could easily be modified and incorporated within a lesson to help prospective teachers become mindful of their own problem solving preferences. Such a lesson could also lead to meaningful discussion about the various characteristics and limitations of different problem solving approaches. In addition, prospective teachers need to be exposed to a variety of problem solving approaches in their mathematics classes. The fact that none of the participating teachers used the manipulating-thestructure strategy when solving the word problems may be indicative of their limited exposure to this strategy. Finally, in order to change teachers' attitudes towards problem solving in general, teacher educators need to adopt a more integrated approach to problem solving instruction. Too often problem solving is taught by what I have called "the recipe method." As stated, this approach identifies certain strategies with certain types of problems, and as a consequence students may come to hold misconceptions about problem solving and what in means to "do" mathematics in general (see Ball 1988). Certainly the recipe approach to teaching problem solving is instructive for young students, however, as students start to develop some mathematical maturity they should come to view problem solving as a deeply integrated and essential mathematical activity rather than a isolated collection of skills or procedures. 


\section{Limitations and Future Research}

I close by mentioning some of the limitations of this study and by suggesting ways future research may address these limitations and extend this work. First, the mathematical histories of the participating teachers were not investigated in this study. While this investigation did diagnose some of the problematic features of prospective teachers' content knowledge and attitudes towards arithmetical and algebraic problem solving strategies, it did not allow me to understand how such features are formed. For instance, the findings associated with the elementary teachers may be explained by the fact that several of these teachers were specializing in mathematics. Such a specialization may have provided these teachers with a diverse mix of mathematical content that could explain their increased knowledge of algebra and their adaptive problem solving behaviors. Also, in the case of the secondary teachers, their strong preference for algebraic methodologies may be the result of the many "algebra-based" courses these teachers are required to complete for their mathematics major.

Second, this study in part assessed teachers' algebraic reasoning (and their potential to support the algebraic development of future students) through arithmetic and algebra word problem solving tasks. Since algebraic reasoning includes a whole host of other activities and understandings (see NCTM 2000) it would be of value to investigate how preservice teachers respond to other tasks that draw from their knowledge of algebra.

Third, the solution strategies that the teachers in this study were asked to evaluate each represented a particular strategy class. Sebrechts et al. (1996) have provided evidence that students often rely on minor or "helper" strategies in the process of constructing a solution to a 
problem. It would be worthwhile to investigate teachers' appreciation of more realistic solutions that incorporated minor strategies, or combinations of two or more different strategies.

Finally, the prospective teachers in this study were grouped according to teaching level only. In order to gain a deeper understanding of the determinants that influence preservice teachers' problem solving behaviors, it would be worthwhile to explore other categorical variables. For instance, I would recommend replicating this study with prospective teachers having various levels of creative ability in order to understand the connection between teachers' creativity and their spontaneous problem-solving approaches. 


\section{References}

Ball, D. L. (1988). Knowledge and reasoning in mathematical pedagogy: Examining what prospective teachers bring to teacher education. Unpublished doctoral dissertation, Michigan State University, East Lansing.

Ball, D. L. (1990). Prospective elementary and secondary teachers' understanding of division. Journal for Research in Mathematics Education, 21(2), 132-144.

Ball, D. L., Lubienski, S. T., \& Mewborn, D. S. (2001). Research on teaching mathematics: The unsolved problem of teachers' mathematical knowledge. In V. Richardson (Ed.), Handbook of Research on Teaching (pp. 433-456). New York, NY: Macmillan.

Ball, D. L., \& McDiarmid, G. W. (1990) The subject matter preparation of teachers. In W. Houston, M. Haberman, \& J. Sikula (Eds.), Handbook of Research on Teachers Education (pp. 437-449). New York, NY: Macmillan.

Bednarz, N., \& Janvier, B. (1993). The arithmetic algebra transformation in problem solving: Continuities and discontinuities. In J. R. Becker \& B. J. Pence (Eds.), Proceedings of the 15th Conference of the International Group for the Psychology of Mathematics Education (Vol. 2, pp. 19-25). San Jose, CA: San Jose State University.

Bednarz, N., \& Janvier, B. (1996). Emergence and development of algebra as a problem solving tool: Continuities and discontinuities with arithmetic. In N. Bednarz, C. Kieran, \& L. Lee (Eds.), Approaches to Algebra: Perspectives for Research and Teaching (pp. 115-136). Dordrecht, The Netherlands: Kluwer Academic Publishers.

Bednarz, N., Radford, L., Janvier, B., \& Lepage, A. (1992). Arithmetical and algebraic thinking 
in problem solving. In W. Geeslin \& K. Grahm (Eds.), Proceedings of the 16th

Conference of the International Group for the Psychology of Mathematics Education (Vol. 2, pp. 65-72). Durham, HN: University of New Hampshire.

Borko, H., Eisenhart, M., Brown, C., Underhill, R., Jones, D., \& Agard, P. (1992). Learning to teach hard mathematics: Do novice teachers and their instructors give up too easily. Journal for Research in Mathematics Education, 23(3), 194-222.

Borko, H., \& Livingston, C. (1989). Cognition and improvisation: Differences in mathematics instruction by expert and novice teachers. American Educational Research Journal, 26(4), 473-498.

Brenner, M. E., Mayer, R. E., Moseley, B., Brar, T., Duran, R., Reed, B. S., \& Webb, D. (1997). Learning by understanding: the role of multiple representations in learning algebra. American Educational Research Journal, 34(4), 663-689.

Brown, C. A., \& Borko, H. (1992). Becoming a mathematics teacher. In D. A. Grouws (Ed.), Handbook of Research on Mathematics Teaching and Learning (pp. 209-239). New York, NY: Macmillan.

Carpenter, T., Fennema, E., Peterson, P., Chiang, C., \& Loef, M. (1989). Using knowledge of children's mathematics thinking in classroom teaching: An experimental study. American Educational Research Journal, 26(4), 499-531.

Carpenter, T., \& Levi, L. (2000). Developing conceptions of algebraic reasoning in the primary grades. (Research Report 00-2). Madison, WI: National Center for Improving Student Learning and Achievement in Mathematics and Science. Retrieved January 20, 2004, from www.wcer.wisc.edu/ncisla 
Clement, J. (1982). Algebra word problem solutions: Thought processes underlying a common misconception. Journal for Research in Mathematics Education, 13(1), 16-30.

Conference Board of the Mathematical Sciences [CBMS]. (2001). The mathematical education of teachers. Providence, RI: American Mathematical Society.

Cummins, D., Kintsch, W., Reusser, K., \& Weimer, R. (1988). The role of understanding in problem solving word problems. Cognitive Psychology, 20, 405-438.

Davis, R. B. (1989). Research studies in how humans think about algebra. In S. Wagner \& C. Kieran (Eds.), Research Issues in the Learning and Teaching of Algebra (pp. 57-59). Hillsdale, NJ: Erlbaum.

De Corte, E., Greer, B., \& Verschaffel, L. (1996). Mathematics teaching and learning. In D. Berliner, \& R. Calfee (Eds). Handbook of Educational Psychology (pp. 491-549). New York: Macmillan.

De Corte, E., Verschaffel, L., \& De Win, L. (1985). Influence of rewording verbal problems on children's problem representations and solutions. Journal of Educational Psychology, 77(4), 460-470.

Discussion document for the twelfth ICMI study. (2000). Educational Studies in Mathematics, 42, 215-224.

Even, R. (1993). Subject matter knowledge and pedagogical content knowledge: Prospective secondary teachers and the function concept. Journal for Research in Mathematics Education, 24(2), 94-116.

Fennema, E., Carpenter, T., Franke, M., Levi, L., Jacobs, V., \& Empson, S. (1996). A 
longitudinal study of learning to use children's thinking in mathematics instruction. Journal for Research in Mathematics Education, 27(4), 403-434.

Fennema, E., \& Franke, M. L. (1992). Teachers' knowledge and its impact. In D. A. Grouws (Ed.), Handbook of Research on Mathematics Teaching and Learning (pp. 147-164). New York, NY: Macmillan.

Filloy, E., \& Sutherland, R. (1996). Designing curricula for teaching and learning algebra. In A. Bishop, K. Clements, C. Keitel, J. Kilpatrick, \& C. Laborde (Eds.), International Handbook of Mathematics Education (pp. 139-160). Dordrecht, The Netherlands: Kluwer Academic Publishers.

Fischbein, E., Deri, M., Nello, M., \& Marino, M. (1985). The role of implicit models in solving verbal problems in multiplication and division. Journal of Research in Mathematics Education, 16(1), 3-17.

Graeber, A. (1999). Forms of knowing mathematics: What preservice teachers should learn. Educational Studies in Mathematics, 38, 189-208.

Graeber, A., Tirosh, D., \& Glover, R. (1989). Preservice teachers' misconceptions in solving verbal problems in multiplication and division. Journal for Research in Mathematics Education, 20(1), 95-102.

Greer, B. (1987). Understanding of arithmetical operations as models of situations. In J. Sloboda \& D. Rogers (Eds.), Cognitive Processes in Mathematics, (pp. 60-80). New York, NY: Oxford University Press.

Greer, B. (1994). Extending the meaning of multiplication and division. In G. Harel \& J. Confrey 
(Eds.), The Development of Multiplicative Reasoning in the Learning of Mathematics, (pp. 61-85). Albany, NY: State University of New York.

Grossman, P. L., Wilson, S. M., \& Shulman, L. S. (1989). Teachers of substance: Subject matter knowledge for teaching. In M. C. Reynolds (Ed.), Knowledge Base for the Beginning Teacher (pp. 23-36). Elmsford, NY: Pergamon Press.

Hall, R., Kibler, D., Wenger, E., \& Truxaw, C. (1989). Exploring the episodic structure of algebra story problem solving. Cognition and Instruction, 6(3), 223-283.

Hatano, G. (1988). Social and motivational bases for mathematical understanding. New Directions for Child Development, 41, 55-70.

Herscovics, N., \& Linchevski, L. (1994). A cognitive gap between arithmetic and algebra. Educational Studies in Mathematics, 27, 59-78.

Howell, D. C. (2002). Statistical methods for psychology ( $5^{\text {th }}$ ed.). Pacific Grove, CA: Duxbury. Hudson, T. (1983). Correspondences and numerical differences between disjoint sets. Child Development, 54, 84-90.

Kaput, J., \& Blanton, M. (2001, December). Algebrafying the elementary mathematics experience. Part I: Transforming task structures. Paper presented at the 12th ICMI Study on "The Future of the Teaching and Learning of Algebra." Melbourne, Australia.

Kaput, J. J. (1989). Linking representations in the symbol systems of algebra. In S. Wagner \& C. Kieran (Eds.), Research Issues in the Learning and Teaching of Algebra (pp. 167-194). Hillsdale, NJ: Erlbaum.

Kieran, C. (1989). The early learning of algebra: A structural perspective. In S. Wagner \& C. 
Kieran (Eds.), Research Issues in the Learning and Teaching of Algebra (pp. 33-56). Hillsdale, NJ: Erlbaum.

Kieran, C. (1992). The learning and teaching of school algebra. In D. A. Grouws (Ed.), Handbook of Research on Mathematics Teaching and Learning (pp. 390-419). New York: Macmillan.

Leinhardt, G., \& Smith, D. A. (1985). Expertise in mathematics instruction: Subject matter knowledge. Journal of Educational Psychology, 77(3), 247-271.

Linchevski, L., \& Herscovics, N. (1996). Crossing the cognitive gap between arithmetic and algebra: Operating on the unknown in the context of equations. Educational Studies in Mathematics, 30, 38-65.

Livingston, C., \& Borko, H. (1990). High school mathematics review lessons: Expert novice distinctions. Journal for Research in Mathematics Education, 21(5), 372-387.

Ma, L. (1999). Knowing and teaching elementary mathematics: Teachers' understanding of fundamental mathematics in China and the United States. Mahwah, NJ: Erlbaum.

MacGregor, M., \& Stacey, K. (1993). Cognitive models underlying students' formulation of simple linear equations. Journal for Research in Mathematics Education, 24(3), 217-232.

MacGregor, M., \& Stacey, K. (1996). Learning to formulate equations for problems. In L. Puig \& A. Gutierrez (Eds.) Proceedings of the 20th conference of the international group for the psychology of mathematics education, (Vol. 3, pp. 289-297). Valencia, Spain.

Mayer, R. E. (1981). Frequency norms and structural analysis of algebra story problems into families, categories, and templates. Instructional Science, 10, 135-175.

Michael, M. D. (2002). Preservice teachers' evaluation of their own problem solving strategies. 
Unpublished paper, West Virginia University, Morgantown.

Mullis, I.V., Martin, M. O., Gonzalez, E. J., Gregory, K. D., Garden, R. A., et al. (2000) Timss 1999: International mathematics report. Boston, MA: The International Study Center.

Nathan, M. J., \& Koedinger, K. R. (2000). Teachers' and researchers' beliefs about the development of algebraic reasoning. Journal for Research in Mathematics Education, 31(2), 168-190.

National Council of Teachers of Mathematics [NCTM]. (2000). Principals and Standards for School Mathematics. Reston, VA: Author.

Nesher, P., \& Teubal, E. (1975). Verbal cues as an interfering factor in verbal problem solving. Educational Studies in Mathematics, 6, 41-51.

Price, E. A., \& Driscoll, M. P. (1997). An inquiry into the spontaneous transfer of problem solving skill. Contemporary Educational Psychology, 22, 472-494.

Reed, S. K. (1999). Word problems: Research and curriculum reform. Mahwah, NJ: Erlbaum.

Riley, M., Greeno, J., \& Heller, J. (1983). Development of children's problem solving ability in arithmetic. In H. P. Ginsburg (Ed.) The Development of Mathematical Thinking, (pp. 153-196). New York, NY: Academic Press.

Ruffell, M., Mason, J., \& Allen, B. (1998). Studying attitude to mathematics. Educational Studies in Mathematics, 35, 1-18.

Schoenfeld, A. H. (1982). Some thoughts on problem solving research and mathematics education. In F. K. Lester \& J. Garofalo (Eds.) Mathematics Problem Solving: Issues in Research. Philadelphia, PA: Franklin Institute Press.

Schoenfeld, A. H. (1992). Learning to think mathematically: Problem solving, metacognition, 
and sense making in mathematics. In D. Grouws (Ed.) Handbook for Research on Mathematics Teaching and Learning, (pp. 334-370). New York, NY: MacMillan Press.

Schwartz, J. (1988). Intensive quantity and referent transforming arithmetic operations. In J. Hiebert \& M. Behr (Eds.), Number Concepts and Operations in the Middle Grades (pp. 41-51). Reston, VA: NCTM.

Sebrechts, M., Enright, M., Bennett, R., \& Martin, K. (1996). Using algebra word problems to assess quantitative ability: Attributes, strategies, and errors. Cognition and Instruction, 14(3), 285-343.

Shulman, L. S. (1986). Those who understand: Knowledge and growth in teaching. Educational Researcher, 4-14.

Shulman, L. S. (1987). Knowledge and teaching: Foundations of the new reform. Harvard Educational Review, 57(1), 1-22.

Slavit, D. (1999). The role of operation sense in the transition from arithmetic to algebraic thought. Educational Studies in Mathematics, 37(3), 251-274.

Simon, M. (1993). Prospective elementary teachers' knowledge of division. Journal for Research in Mathematics Education, 24(3), 233-254.

Simon, M., \& Blume, G. (1996). Justification in the mathematics classroom: A study of prospective teachers. Journal of Mathematical Behavior, 15, 3-31.

Sowder, L. (1988). Children's solutions of story problems. Journal of Mathematical Behavior, 7 , 227-238.

Stienberg, R. M., Sleeman, D. H., \& Ktorza, D. (1990). Algebra students’ knowledge of 
equivalence of equations. Journal for Research in Mathematics Education, 22(2), 112121.

Sutherland, R. (in press). A dramatic shift of attention: From arithmetic to algebraic thinking. In J. Kaput, D. Carraher, \& M. Blanton (Eds.), Employing Children's Natural Powers to Build Algebraic Reasoning in the Context of Elementary Mathematics. Mahwah, NJ: Erlbaum.

Thipkong, S., \& Davis, E. J. (1991). Preservice elementary teachers' misconceptions in interpreting and applying decimals. School Science and Mathematics, 91(3), 93-99.

Thompson, A. G. (1992). Teachers' beliefs and conceptions: A synthesis of the research. In D. A. Grouws (Ed.), Handbook of Research on Mathematics Teaching and Learning (pp. 127-146). New York, NY: Macmillan.

Van Dooren, W., Verschaffel, L., \& Onghena, P. (2002). The impact of preservice teachers' content knowledge on their evaluation of students' strategies for solving arithmetic and algebra word problems. Journal for Research in Mathematics Education, 33(5), 319-351.

Van Dooren, W., Verschaffel, L., \& Onghena, P. (2003). Preservice teachers preferred strategies for solving arithmetic and algebra word problems. Journal of Mathematics Teacher Education, 6(1), 27-52.

Verschaffel, L., De Corte, E., \& Borghart, I. (1997). Pre-service teachers' conceptions and beliefs about the role of real-world knowledge in mathematical modeling of school word problems. Learning and Instruction, 7(4), 339-359.

Wilson, M. (1994). One preservice secondary teachers' understanding of function: The impact of 
a course integrating mathematical content and pedagogy. Journal for Research in Mathematics Education, 25(4), 356-370.

Wilson, S. M., Shulman, L. S., \& Richert, A. E. (1987). 150 ways of knowing: Representations of knowledge in teaching. In J. Calderhead (Ed.), Exploring Teacher Thinking (pp. 104-124). Sussex: Holt, Rinehart, \& Winston. 
Appendix A

\section{Word Problem Test Items}

*1. A primary school with 345 pupils had a sports day. The pupils could choose between skating, swimming or a bicycle ride. Twice as many pupils selected skating, as did the bicycle ride. And there were 30 pupils less who chose swimming than skating. If 120 pupils went swimming, how many chose skating and the bicycle ride?

2. Participants in a timed fishing contest were competing for the largest total catch. The contestants were only allowed to count carp, bass and catfish. Three times as many carp were caught than catfish. And 16 more bass were caught than carp. If 34 bass were caught out of 58 fish, how many carp and catfish each were caught?

*3. A large company employs 372 people. There are 4 times as many floor workers as clerks. And 18 clerks more than managers. How many floor workers, clerks and managers are there in the company?

4. A car dealership sold 16 cars in one month. There were 2 times as many vans sold than sedans, and 4 less sedans than trucks. How many vans, sedans and trucks each were sold?

*5. In 15 years, Frederick will be twice as old as Tonya will be then. If Frederick is 37 years old now, how old is Tonya?

6. In 5 years Mrs. Patrick will have taught school three times longer as Mr. Wilson will have then. If Mrs. Patrick has been teaching for 13 years, how long has Mr. Wilson been teaching?

*7. Last year, farmer Adams owned a lot of land that was 15 acres smaller than the land of farmer Best. This year, farmer Adams bought 20 acres of extra land, while farmer Best 
doubled his area of land. Now the land of farmer Adams is only 14 acres smaller than that of farmer Best. How much land did each farmer have last year?

8. Last week Melody sold 20 fewer boxes of cookies than her sister. This week Melody's sister sold 7 boxes, while Melody sold twice as many as last week. As a result, Melody has now sold 17 fewer boxes than her sister. How many boxes of cookies did Melody sell last week?

*9. The cashier of a cinema sold $\$ 443$ in tickets in one evening. That evening 30 adult tickets were sold, at $\$ 6.50$ per ticket. How many child tickets were sold that evening if you know that a child ticket is $\$ 2.50$ cheaper than an adult ticket?

10. A small online shirt business sells both short sleeve and log sleeve shirts. Last month the business brought in $\$ 616$ in sales. That month 11 long sleeve shirts were sold at $\$ 20$ per shirt. If the price for a short sleeve shirt was $\$ 8$ less than a long sleeve shirt, how many short sleeve shirts were sold last month?

*11. A furniture factory uses large and small trucks to transport 632 beds from California to Washington. A large truck can haul 26 beds, while a small truck can haul 20 beds. In the truck convoy that transported the beds there were 4 more small trucks that large trucks. How many trucks of each type were in the convoy?

12. The opening night of a musical generated $\$ 912$ in tickets sales. The price for an adult ticket was $\$ 15$ and a child ticket sold for $\$ 8$. If there were twice as many adults than children, how many adults attended the musical? How many children attended the musical?

\footnotetext{
* Items translated from Van Dooren et al.
} 


\section{Appendix B}

\section{Solution Questionnaire Items}

Problem one: Last week Melody sold 20 fewer boxes of cookies than her sister. This week Melody's sister sold 7 boxes, while Melody sold twice as many as last week. As a result, Melody has now sold 17 fewer boxes than her sister. How many boxes of cookies did Melody sell last week?

Solutions:

\begin{tabular}{lll}
\hline melody & $\frac{\text { siater }}{30+7}$ & $37 \cdot 30=7$ to low \\
$10(3)$ & $26 \cdot 7$ & $33-18=15$ too low \\
$6(3)$ & $25+7$ & $32-15=17$ correct \\
$5(3)$ & 5
\end{tabular}

Melody sold 5 boves last weete. - out of $10 \mathrm{pts}$

$$
\begin{aligned}
& \text { Let } x=\text { number of boxes melody sold hotweek } \\
& x+20+7=3 x+17 \\
& x+27=3 x+17 \\
& 10=2 x \\
& x=5 \\
& \text { Meliog sold } 5 \text { baxes last weet }
\end{aligned}
$$
-.- out of 10 pts.

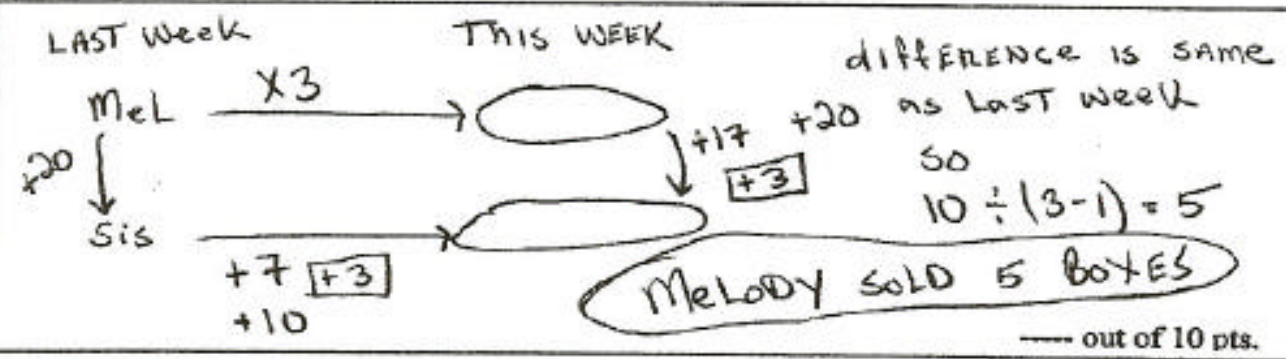

Please justify the highest score you gave:

Figure B1. Item one of the solution questionnaire. 
Problem two: The opening night of a musical generated $\$ 912$ in ticket sales. The price for an adult ticket was $\$ 15$ and a child ticket sold for $\$ 8$. If there were twice as many adults than children, how many adults attended the musical? How many children attended the musical?

Solutions:

$$
\begin{aligned}
& \text { Let } A=\text { adules } \\
& C=\text { ctulder } \\
& A=2 C \\
& 15 A+8 C=9 / 2 \\
& 15(2 c)+8 c=912 \\
& 30 C+8 C=9 / 2 \\
& \begin{aligned}
\frac{38 C}{38} & =\frac{912}{38} \\
c & =24
\end{aligned} \\
& \text { childen }=24 \\
& \text { aduls }=48 \\
& \text {...-. out of } 10 \mathrm{pts} \text {. }
\end{aligned}
$$

What if numser of Adults SAME AS ChILdREN,

Adults WoulP PAY DOUBLE to EET $\$ 912$

$30+8=\$ 38$ fOR ONE ChILD AND OWE ADWLT

$912 / 38=24$ ChILAREN

$24(2)=48$ ADULTs

-.-- out of $10 \mathrm{pts}$.

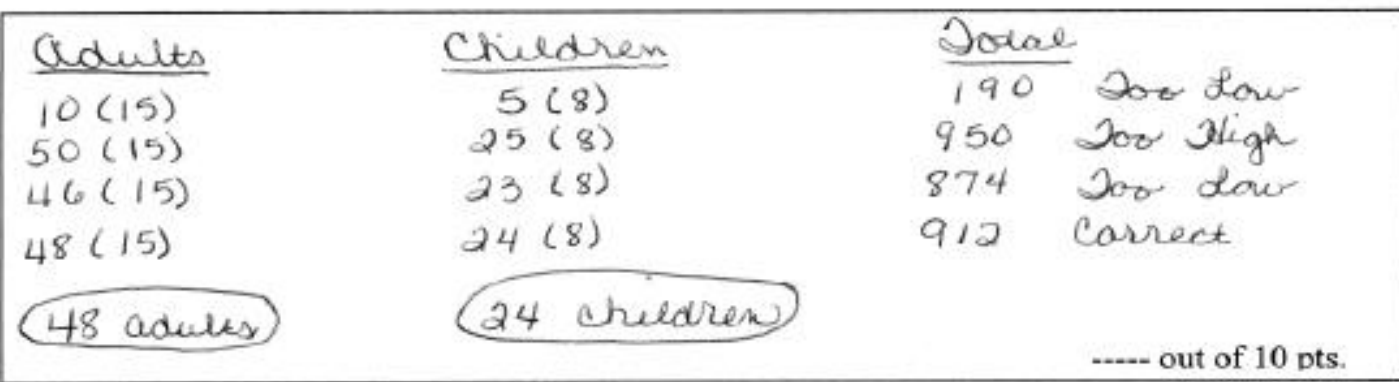

Please justify the highest score you gave:

Figure B2. Item two of the solution questionnaire. 
Problem three: Participants in a timed fishing contest were competing for the largest total catch. The contestants were allowed to count carp, bass and catfish. Three times as many carp were caught than catfish. And 16 more bass were caught than carp. If 34 bass were caught out of 58 fish, how many carp were caught? How many catfish were caught?

Solutions:

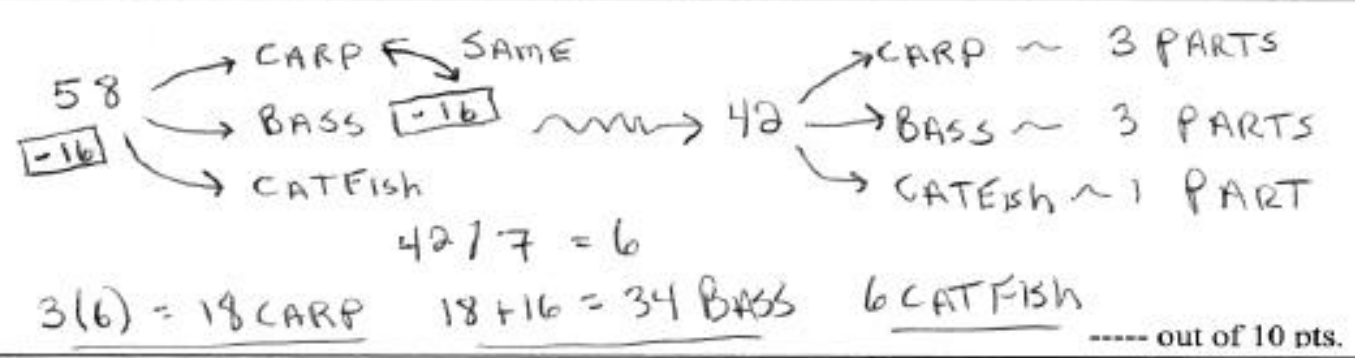

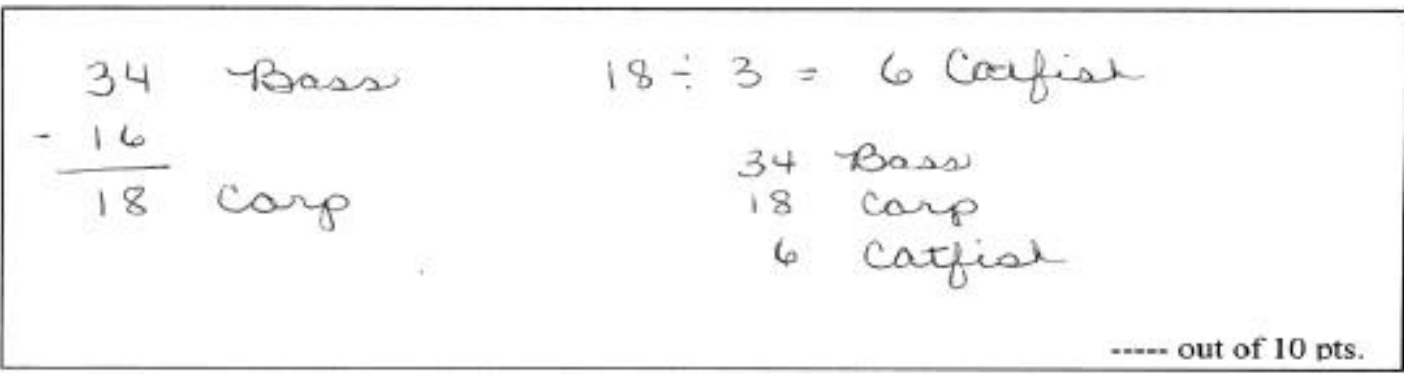

$$
\begin{array}{cc}
x=\text { catpise } & \\
x+3 x+34=58 & \text { catts }=6 \\
4 x+34=58 & \text { carp }=3 \\
4 x=24 & \text { bass }= \\
x=6 &
\end{array}
$$

Please justify the highest score you gave:

Figure B3. Item three of the solution questionnaire. 
Problem four: In 5 years Mrs. Patrick will have taught school three times longer as Mr. Wilson will have then. If Mrs. Patrick has been teaching for 13 years, how long has Mr. Wilson been teaching?

\section{Solutions:}

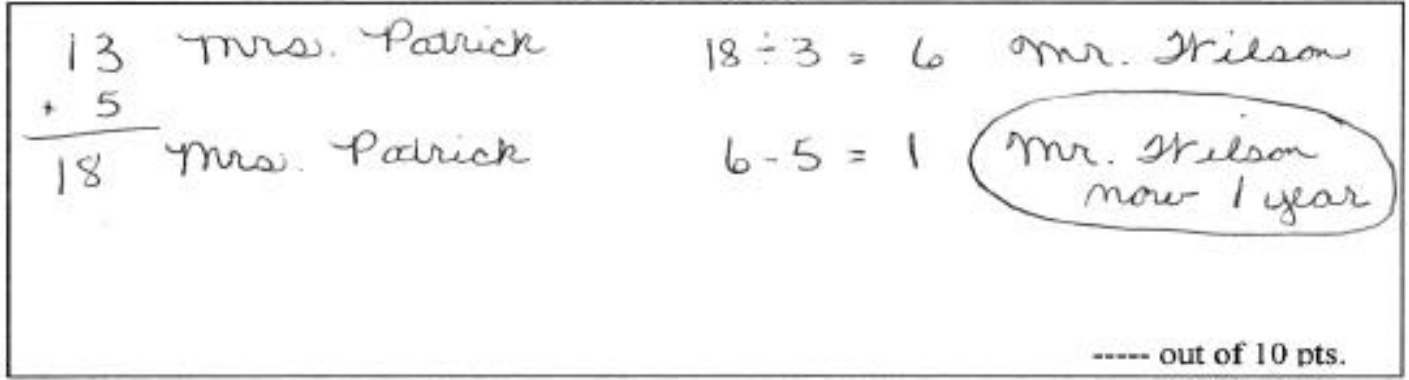

EVERY YEAR MR. W has TAMGhT, thE YEARS MRS. $P$

WILL hAVE TAMGST IW 5 YEARS WILL GROW BY 3 . If

MAS.P hAS BEEN TEAChING fOR $13-3=10$ YEARSMA.W

MAS BEEN TIAChINE For io $+5=15$ is $/ 3=5 \quad 5-5=0$ yEARS NEED tO AOD I to MR. W $O+1=1$ YEAR

-...- out of 10 pts.

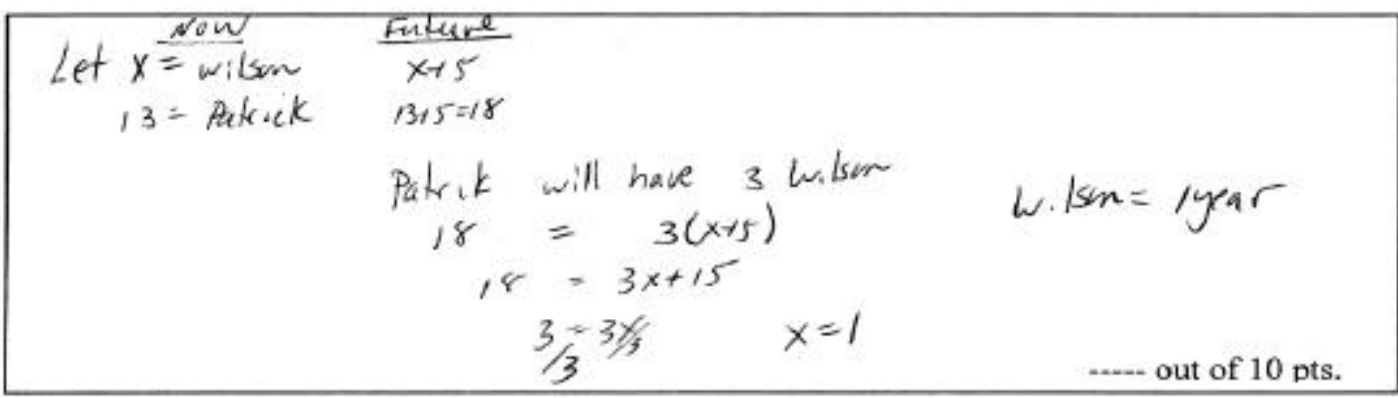

Please justify the highest score you gave:

Figure B4. Item four of the solution questionnaire. 
Problem five: A small online shirt business sells both short sleeve and long sleeve shirts. Last month the business brought in $\$ 616$ in sales. That month 11 long sleeve shirts were sold at $\$ 20$ per shirt. If the price for a short sleeve shirt was $\$ 8$ less than a long sleeve shirt, how many short sleeve shirts were sold?

Solutions:

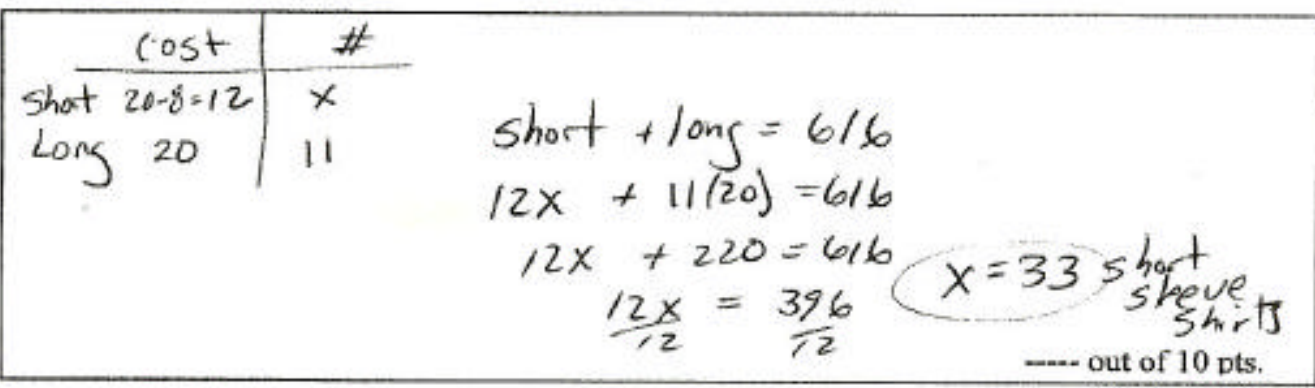

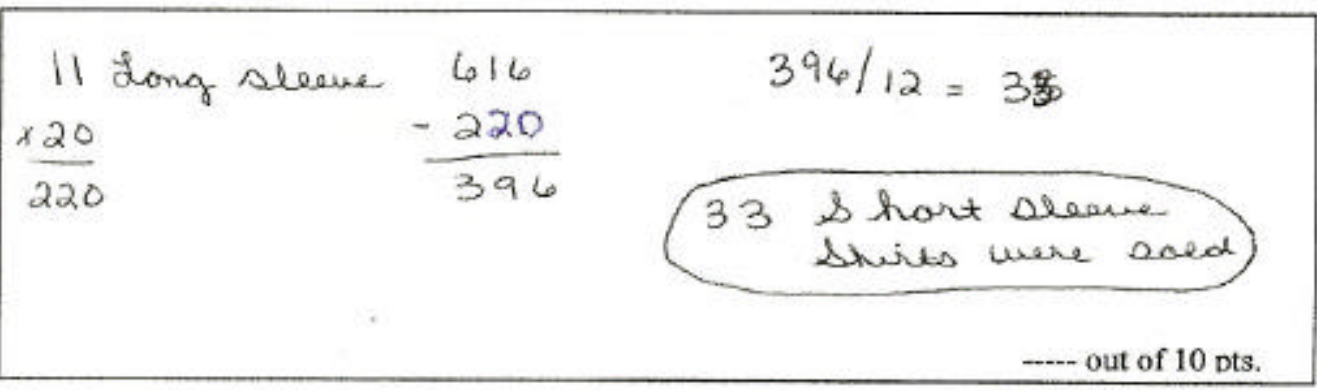

What if II ShORT SLEEVE ShIRTS WERE SOLD tor \$2O

$$
\begin{aligned}
& \|(20)=220 \text { ShORT } \begin{array}{l}
616-440=176 \quad 176 / 8=22 \\
20-12=8
\end{array} \\
& \text { MHO TOTAL MEED 22 MORE ShORT SLELVE } \\
& \text { SWRTS } 11+22=33
\end{aligned}
$$

-.... out of 10 pts.

Please justify the highest score you gave:

Figure B5. Item five of the solution questionnaire. 
Problem six: A car dealership sold 16 cars in one month. There were 2 times as many vans sold than sedans, and 4 less sedans than trucks. How many vans, sedans and trucks each were sold?

Solutions:

\begin{tabular}{|c|c|c|c|c|}
\hline \multirow{2}{*}{$\frac{\operatorname{sedana}}{5}$} & \multirow{2}{*}{$\frac{\text { Vama }}{10}$} & \multirow{2}{*}{$\frac{\text { Ounces }}{9}$} & \multicolumn{2}{|c|}{ Jotal } \\
\hline & & & 24 & ( Dos muen) \\
\hline 4 & 8 & 8 & 20 & (Nos Muck) \\
\hline & 6 & & 16 & Correct \\
\hline & & & $\ldots$ & ut of 10 pts. \\
\hline
\end{tabular}

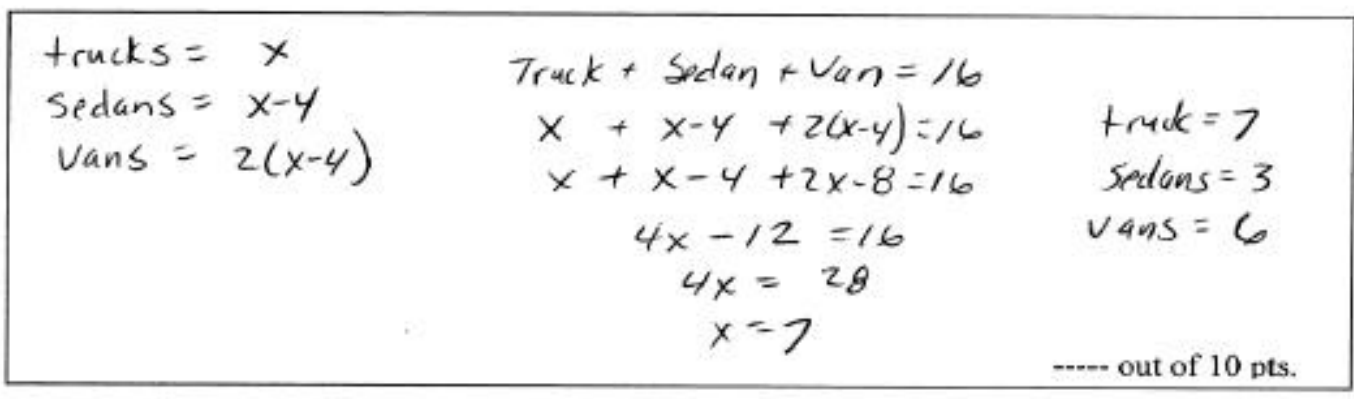

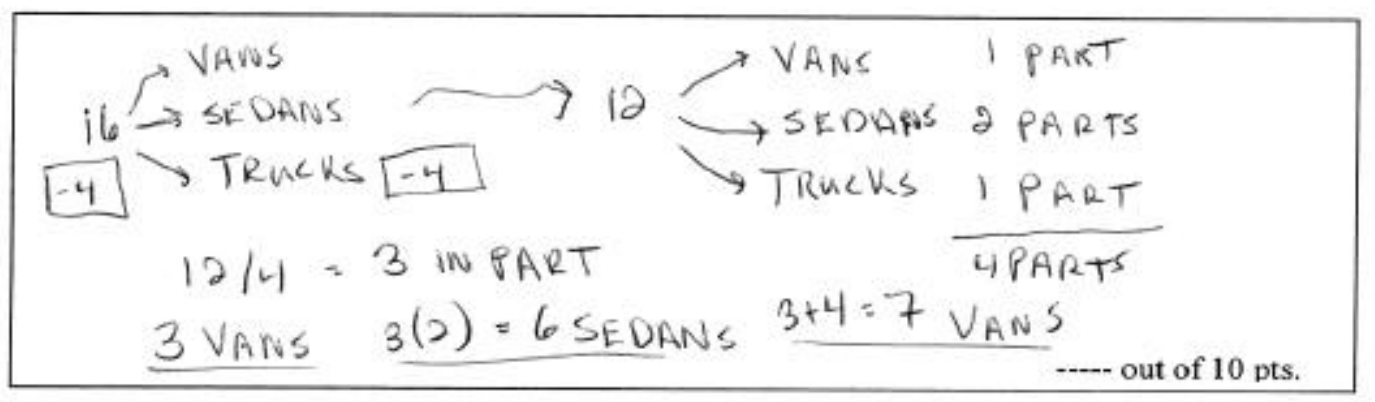

Please justify the highest score you gave:

Figure B6. Item six of the solution questionnaire. 
Appendix C

\section{Interview Protocol}

1. How would you describe your problem solving abilities?

2. How do you make decision about which strategies to use?

3. If you were assessing the problem solving abilities of your own students, what kinds of evidence would you need to discriminate between "good" problem solvers and "bad" problem solvers?

4. What are some of the characteristics of an "effective" problem solving strategy?

5. Did you understand the problems that were contained in the Solution Questionnaire, if not, which questions did you not understand?

6. Considering some of the strategies that you scored high (Participant will examine his or her responses to the solution questionnaire.), what aspects of these strategies warranted this high score?

7. Considering some of the strategies that you scored low (Participant will examine his or her responses to the solution questionnaire.), what aspects of these strategies warranted a low score?

8. What types of skills or procedures would you focus on when teaching and/or demonstrating problem solving strategies to students?

9. Are there any additional comments you would like to add that were not discussed here today? 